\title{
ASSESSING GEOTECHNICAL CENTRIFUGE MODELLING IN ADDRESSING VARIABLY SATURATED FLOW IN SOIL AND FRACTURED ROCK
}

\author{
Brendon R. Jones ${ }^{*, 1}$, Luke B. Brouwers ${ }^{1}$, Warren D. Van Tonder ${ }^{1}$, and Matthys A. Dippenaar ${ }^{1}$ \\ ${ }^{I}$ Engineering Geology and Hydrogeology, Department of Geology, University of Pretoria, Private Bag X20, \\ Hatfield, 0028, Pretoria, Gauteng, South Africa
}

*Corresponding author.Tel.: +27 (0)12 420 2454; e-mail address: bren.r.jones@gmail.com

\begin{abstract}
The vadose zone typically comprises soil underlain by fractured rock. Often, surface water and groundwater parameters are readily available, but variably saturated flow through soil and rock are oversimplified or estimated as input for hydrological models. In this paper, a series of geotechnical centrifuge experiments are conducted to contribute to the knowledge gaps in: (i) variably saturated flow and dispersion in soil; and (ii) variably saturated flow in discrete vertical and horizontal fractures. Findings from the research show that the hydraulic gradient and not the hydraulic conductivity is scaled for seepage flow in the geotechnical centrifuge. Furthermore, geotechnical centrifuge modelling has been proved as a viable experimental tool for the modelling of hydrodynamic dispersion as well as the replication of similar flow mechanisms for unsaturated fracture flow, as previously observed in literature. Despite the imminent challenges of modelling variable saturation in the vadose zone, the geotechnical centrifuge offers a powerful experimental tool to physically model and observe variably saturated flow. This can be used to give valuable insight into mechanisms associated with solid-fluid interaction problems under these conditions. Findings from future research can be used to validate current numerical modelling techniques and address the subsequent influence on aquifer recharge and vulnerability, contaminant transport, waste disposal, dam construction, slope stability and seepage into subsurface excavations.
\end{abstract}

Keywords: Unsaturated flow; fracture flow; dispersion; hydraulic conductivity; flow mechanism; smooth parallel plate model. 


\section{INTRODUCTION}

The implications of improved understanding of variably saturated flow through geologic media are numerous, especially given the complexity, heterogeneity and anisotropy of the vadose zone. Worldwide surface infrastructure is extending skywards as well as to greater depths below the surface. The increased need for natural resources also implies deeper mines, larger dewatering cones around mines, dewatering of rock aquifers, increased size and toxicity of waste disposal sites, and deep nuclear waste repositories. Prospects of deep hydraulic fracturing (fracking) for shale gas or coal-bed methane raises questions about upward migration of hydrocarbon liquids and gases, potentially rendering groundwater aquifers susceptible to contamination. These anthropogenic activities impact on the hydrosphere and lithosphere and need to be quantified to determine negative impacts and remedial measures. The quantification of water movement through rock masses also has enormous economic implications. Water inflow into deep mines, building basements, underground tunnels (water and transport), subsurface waste disposal sites (nuclear and other) and large rock caverns (hydro-electric and storage facilities) needs to be quantified to create safe operational conditions.

In order to understand the specific influences of geologic media on variably saturated flow in the subsurface, one needs to directly measure or observe the behaviour of fluids. To achieve this, physical modelling of fluid flow through artificial or natural geologic media, simulated at a smaller laboratory scale, provides the best approach. Physical models would allow one to directly measure or observe the influence that different properties will have on fluid flow. If the model is proportionately scaled and one is aware of the assumptions made and the implications on the modelling results, then the model may ultimately be regarded as a representative simplification of the real system (Silberhorn-Hemminger et al. 2005). Small scale physical models are more repeatable and less costly than large scale tests (Culligan-Hensley and Savvidou 1995). If the model is considered to be representative, then the results will aid greatly to the understanding of fluid flow through geologic media.

The research presented in this paper aims at assessing the geotechnical centrifuge in modelling and addressing solid-fluid interaction problems associated with variable saturation in the vadose zone. Experimental work described in this paper seeks to define some fundamental conceptual models. The aim is achieved by testing 
some of these fundamental conceptual models associated with both soils and fractured rock, which involve addressing the following set of objectives during the centrifuge modelling:

1. Revisiting the scaling issue of hydraulic conductivity or hydraulic gradient in the centrifuge at saturated conditions;

2. Assessing the validity of transverse hydrodynamic dispersion in unsaturated conditions;

3. Investigating the validity in using the smooth parallel plate model in replicating unsaturated fracture flow mechanisms.

Findings from the research address some issues as to whether it is plausible to observe or replicate recorded field characteristics in a geotechnical centrifuge. The geotechnical centrifuge model tests were performed at various scales using the 150 G-ton geotechnical centrifuge housed in the Department of Civil Engineering at the University of Pretoria, of which the details of the centrifuge facility are described by Jacobsz et al. (2014).

\section{LITERATURE}

\subsection{Variably saturated subsurface flow}

Flow (seepage), wetting (imbibition) and drying (drainage) in unsaturated media becomes increasingly complex. The potential for seepage in unsaturated conditions is driven by a combination of the gravitational potential and the matrix potential (suction). The seepage through pores is largely dependent on the non-linear relationship between suction, moisture content and hydraulic conductivity, which is unique to each soil sample (Nimmo 2006; Rumynin 2011). Literature on the topic is abundant and well documented internationally and in South African context (e.g. Dippenaar 2012; Dippenaar 2014; Dippenaar et al. 2014).

In fractured media, seepage occurs both through the matrix and fractures where generally, the hydraulic conductivity of the matrix is lower than the hydraulic conductivity of a fracture (Singhal and Gupta 2010). However, flow in a fracture does not follow the same capillary-control as does flow in porous media, where instead the hydraulic conductivity of fractures is dependent on the fracture aperture, roughness, infill, stress conditions and geometrical properties (Berkowitz 2002). In natural conditions, fractures are both rough and irregular but can be expressed by a simple model concept of two smooth parallel plates. Literature is abundant 
on the topics of the smooth parallel plate model and the associated cubic law topics (e.g. Bear 1972; Berkowitz 2002; Dippenaar and Van Rooy 2016; Gudmundsson et al. 2003; Hoek and Bray 1981; Indraratna and Ranjith 2001; Liu et al. 2013; Neuman 2005; Silberhorn-Hemminger et al. 2005; Singhal and Gupta 2010; Weiss et al. 2006; Witherspoon et al. 1980; Zimmerman and Bodvarsson 1996). Importantly, Singhal and Gupta (2010) state that the assumptions of the cubic law usually do not hold well in natural conditions, with the validity of cubic law discussed by several researchers (Aydin 2001; Cook 1992; Dippenaar and Van Rooy 2016; Lee and Farmer 1993; Pyrak et al. 1985; Raven and Gale 1985; Sisavath et al. 2003; Witherspoon 1986).

Several flow mechanisms have been observed to occur in fractures at unsaturated conditions, as observed in flow visualization experiments and conceptual modelling studies. Ghezzehei (2004) states that for an idealized smooth fracture surface the most important mechanisms are; film flow, rivulet flow, and sliding of droplets. Film flow (as presented by e.g.: Or and Tuller 2000; Tokunaga and Wan 1997; Tokunaga and Wan 2001) occurs as thin films of water flowing along the fracture surface without having to fully saturate the fracture, and can occur over a wide range conditions within unsaturated rocks. The thickness of the film depends on the degree of saturation, where an increase in saturation results in thicker films. Droplet or liquid bridge flow can occur, as hypothesised by Doe (2001), and echoed by Or and Ghezzehei (2007), whereby fluid spans both walls of the fracture or drops that occur separately on adjacent walls within a fracture. An additional flow mechanism is that of rivulets, of which there are three possible scenarios, as initially presented by $\mathrm{Su}$ et al. (1999) and further by Dragila and Weisbrod (2003). The three scenarios are dependent on flow rates, whereby: at low flow rates continuously snapping rivulets form liquid bridges within the fracture; at medium flow rates rivulets form and only snap at the fracture's end; and at high flow rates were rivulets that form are maintained throughout the fracture. Although Doe (2001) presented that it is the wettability of the material that separates film and droplet flow, recent research shows that different flow mechanisms can occur in fractures as presented by Dragila et al. (2016) who showed the co-existence of droplets and film flow in vertical epikarst microfractures. Ghezzehei (2004) showed how differing flow mechanisms can also occur over a wide range of contact angles, and fluxes. Furthermore, the formation of these flow mechanisms is dependent on various factors, including the force interactions between gravity, surface tension, capillary pressure, and viscous forces, which can result in complex flow phenomena, such as episodic fluxes, intermittent fluxes and preferential flow paths (Dragila and Weisbrod 2003; Hakami and Larsson 1996; Su et al. 1999). 


\subsection{Geotechnical centrifuge modelling}

A geotechnical centrifuge offers a powerful physical modelling technique that is capable of replicating gravitational dependent processes between a scaled model and prototype conditions (Phillips 1995; Taylor 1995). This is done by accelerating a model an equivalent $N$ times Earth's gravitational field $g$ (ca. $9.81 \mathrm{~m} / \mathrm{s}^{2}$ ) and results in the model being subjected to a centrifugal acceleration $\mathrm{Ng}$. The fundamental requirement for the model and prototype to be similar is that the dimensionless groups are identical and similitude is achieved. A plethora of appropriate scaling laws are used for centrifuge modelling, including: linear dimensions; stress; time; Darcy's Law; and Reynolds Number, which have been discussed in detail by Butterfield (2000), CulliganHensley and Savvidou (1995), Kumar (2007), Taylor (1995), Phillips (1995) and Garnier et al. (2007).

\subsubsection{Hydraulic conductivity and contaminant transport modelling}

Conventional methods used to measure the hydraulic properties of soils rely on gravitational acceleration or an applied pressure gradient to drive flow through a sample. Such methods are often time consuming, tedious and limited to a small range of measurable hydraulic conductivity $(K)$ values (Šimůnek and Nimmo 2005). However, use of a geotechnical centrifuge allows for simple flow apparatus, decreased experimental time, larger range of measurable $K$ values, and the ability to simulate overburden pressure largely due to the development of the steady state centrifuge method (Barry et al. 2001; Basha and Mina 1999; Nimmo 1990; Nimmo et al. 1992; Nimmo and Mello 1991; Nimmo et al. 1987; Šimůnek and Nimmo 2005; Singh and Gupta 2000; Zornberg and McCartney 2010). In terms of physical modelling of contaminant transport, the geotechnical centrifuge offers an opportunity to bridge laboratory and field experiments by overcoming the limitations of these methods by being able to model complex problems under repeatable conditions using large sample sizes, and better control of experimental boundary conditions, while maintaining the ability to perform in flight monitoring (Mattson et al. 2010)

In determining the dispersion scaling factor, the mechanical dispersion coefficient cannot be considered a material property because it is a function of both interstitial velocity and pore size (Culligan-Hensley and Savvidou 1995). However, Hensley and Randolph (1994) investigated dispersion in a geotechnical centrifuge, with results indicating that there is a scaling error for dispersion. The authors critically evaluated the derivation 
of the scaling factor for dispersion and concluded that it is still possible to relate concentration distributions using a scaling factor ranging between $N$ and $N^{1 / 2}$ for dispersion.

The above discussion deals with a well-established knowledge of miscible flow in a geotechnical centrifuge. However, modelling of immiscible fluid flow in the geotechnical centrifuge is less prevalent and is mainly in the form of experiments investigating Non-Aqueous Phase Liquids (NAPL) movement. Culligan and Barry (1998) show that in order for similitude, the appropriate scaling factors, for the Capillary number, Bond number and Stokes number (dimensionless parameters calculated by topical textbooks, including for e.g.; Poehls and Smith 2011) are dependent on whether the characteristic length of the system being investigated is macroscopic or microscopic. In scenarios where the characteristic length is macroscopic, the appropriate scaling factors for the Capillary and Bond number are constant, resulting in the similitude between the model and the prototype. However, if the characteristic length is microscopic (i.e. pore throat size, fracture aperture), then the Capillary and Bond should both be scaled by a factor of $N$, which may result in failure of geometric or kinematic similitude elsewhere. Despite this violation of similitude, Culligan and Barry (1998) suggest that it is still possible to use the geotechnical centrifuge in performing parametric experiments on immiscible fluid flow.

\subsubsection{Modelling of flow through rock}

Modelling of soil behaviour in the geotechnical centrifuge is well studied with a large amount of studies available. Unfortunately, the same cannot be said for centrifuge modelling of rock masses, with literature limited to geotechnical problems of rock slopes or mining instabilities (e.g. Cecconi et al. 2006; Chen et al. 2006; Chikatamarla et al. 2006; Einstein et al. 1990; Günzel and Davies 2006; Itoh et al. 2006; Joseph and Einstein 1988; Li et al. 2014; Stone et al. 2013). This is due to the inability of using the prototype material in the model due to the discontinuous nature of a rock mass and the lack of suitable analogue material alternative (Chen et al. 2006). Adopting the reasoning of Culligan and Barry (1998) for the problem of fracture flow, the ratio of body gravity to capillary forces must be correct in order to simulate fluid invasion in a fracture, and therefore the fracture aperture does not scale. Once fluid is in the fracture, similitude will depend on the flow mechanisms themselves. Adopting fractures as microscopic lengths from the reasoning of Culligan and Barry (1998), Levy et al. (2002) investigated dense-NAPL invasion into a fracture. The authors concluded that there is good agreement between scaled centrifuge data and prototype data provided that inertial forces in the fracture remain 
negligible. From these findings, Levy et al. (2003) formulated an equation to quantify the influence of inertial forces by three regime criterion, in addition to the scaling laws proposed by Culligan and Barry (1998). Beyond the discussed modelling of rock slope stability problems, and dense-NAPL experiments, no literature exists relating to the modelling of unsaturated fracture flow in the geotechnical centrifuge.

\section{MATERIALS AND METHODS}

A series of centrifuge experiments evaluating some fundamental conceptual models of subsurface flow in both soil and rock are developed:

- Experiment 1 attempts to verify scaling laws of seepage flow in a geotechnical centrifuge. Unlike the subsequent experiments, this test was conducted in saturated conditions and sought to address the uncertainties in scaling of hydraulic conductivity or hydraulic gradient in the centrifuge. It was paramount to address this issue before attempting to address unsaturated conditions

- Experiment 2 expands on the first experiment and addresses the effect an increased gravitational acceleration level has on transverse hydrodynamic dispersion under unsaturated conditions, and whether the centrifuge is a viable tool in modelling dispersion problems.

- Experiment 3 examines the fundamental conceptual model of a clean smooth parallel plate for a discrete fracture at vertical and horizontal orientations. Due to the novelty of unsaturated fracture flow in the centrifuge, it is vital to first validate the fundamental conceptual models and whether similar flow mechanisms presented in literature occur. Therefore, to emulate a smooth clean parallel plate model in a centrifuge, acrylic Plexiglas sheets are selected due to the transparency and machinability of the material.

\section{EXPERIMENT 1: 1-DIMENSIONAL VERTICAL FLOW THROUGH SOIL}

\subsection{Model preparation and test procedure}

The model developed by Van Tonder (2016), shown in Figure 1, is used to determine the permeability of a soil sequence in a centrifuge and entails a $1000 \mathrm{~mm}$ tall acrylic Plexiglas cylinder with an inner diameter of $140 \mathrm{~mm}$ placed inside an aluminium strongbox. The uniform fine-grained sand has an average particle size of $135 \mu \mathrm{m}$ and 
average reported permeability of $1.8 \times 10^{-4} \mathrm{~m} / \mathrm{s}$ to limit the number of variables (Archer 2014). The sand is placed in de-aired water to a height of $600 \mathrm{~mm}$ above a $50 \mathrm{~mm}$ base filter. Three pore pressure transducers (PPTs) are spaced at $200 \mathrm{~mm}$ intervals in the soil, with the bottom PPT placed above the filter and the top PPT placed $200 \mathrm{~mm}$ below the soil surface. Solenoid valves (electronic tap) are connected to waste water outlet pipes at the base of the model to control the hydraulic conductivity experiment procedure.

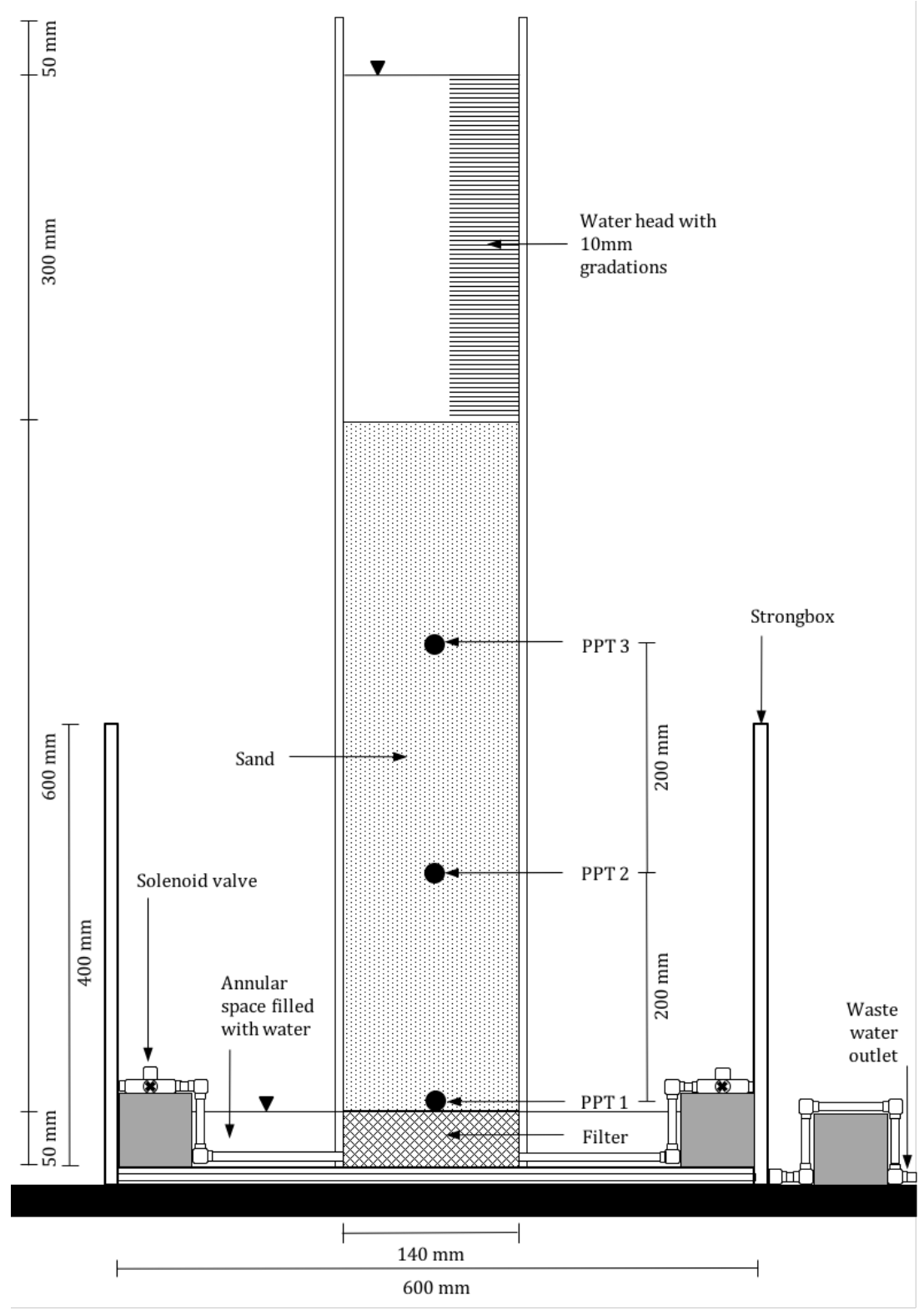

Figure 1. Test configuration for experiment 1: Modelling hydraulic conductivity or hydraulic gradient

The geotechnical centrifuge is accelerated to $23 \mathrm{~g}$, where consolidation is allowed to occur to obtain constant pore water pressures. The initial water level $\left(h_{l}\right)$ is recorded and the solenoid valves is opened to initiate flow through the model. To determine steady state flow, the pore pressures are monitored in-flight for a linear reading. 
After the water level had dropped sufficiently, the solenoid valves are closed and the final water level $\left(h_{2}\right)$ is recorded. The pore pressures are allowed to stabilise again before repeating the same procedure. Once the centrifuge is stopped, the sample thickness and final water level are recorded before immediately filling the cylinder with de-aired water to conduct a $1 \mathrm{~g}$ experiment. The initial water level is again recorded before opening the solenoid valves, where the water level is then allowed to fall to the same final level recorded in the $23 \mathrm{~g}$ experiment before the solenoid valves are closed and the test completed.

\subsection{Results and discussion}

The recorded physical observations from Van Tonder (2016) for both the $23 \mathrm{~g}$ and $1 \mathrm{~g}$ tests are presented in Table 1, where a total settlement of $4 \mathrm{~mm}(92 \mathrm{~mm}$ at prototype scale) occurs. During the first run of the $23 \mathrm{~g}$ experiment, the head dropped $0.14 \mathrm{~m}(3.22 \mathrm{~m})$ in 139 seconds $(20.42$ hours $)$, while an additional $0.097 \mathrm{~m}$ (1.94 $m$ ) head fell in 82 seconds (12.05 hours) during the second run, resulting in a total fall in head of $0.237 \mathrm{~m}(5.45$ $m$ ) in 222 seconds (32 hours). For the $1 \mathrm{~g}$ test, a fall of head of $0.24 \mathrm{~m}$ occurs significantly slower at 1911 seconds.

Table 1. The recorded physical observations at $1 \mathrm{~g}$ and $23 \mathrm{~g}$.

\begin{tabular}{cccccc}
\hline Test & $h_{l}(\mathrm{~m})$ & $h_{2}(\mathrm{~m})$ & Time $(\mathrm{sec})$ & $\begin{array}{c}\text { Initial Sample } \\
\text { Thickness }(\mathrm{m})\end{array}$ & $\begin{array}{c}\text { Final Sample } \\
\text { Thickness }(\mathrm{m})\end{array}$ \\
\hline $23 \mathrm{~g}$ ( $^{\text {st }}$ Run & 0.89 & 0.75 & 139 & 0.594 & 0.59 \\
$23 \mathrm{~g} \mathrm{2}{ }^{\text {nd }}$ Run & 0.75 & 0.65 & 82 & 0.59 & 0.59 \\
$1 \mathrm{~g}$ & 0.90 & 0.66 & 1911 & 0.59 \\
\hline
\end{tabular}

\subsubsection{Pore pressures}

The pore pressures for the $23 \mathrm{~g}$ and $1 \mathrm{~g}$ experiments are shown by Figure $2 \mathrm{a}$ and Figure $2 \mathrm{~b}$, respectively. For both experiments, all the PPTs rapidly drop after the solenoid valves are opened and then decrease at a constant rate during steady state flow before rapidly stabilising to new pore pressure values once the solenoid valves are closed. Furthermore, PPT 1 experienced the maximum pore pressures when the solenoid valves are closed and the greatest drop in pressure when the solenoid valves are opened, while PPT 2 records intermediary pore pressures and pressure drops and PPT3 records the lowest pore pressures and pressure drops. 

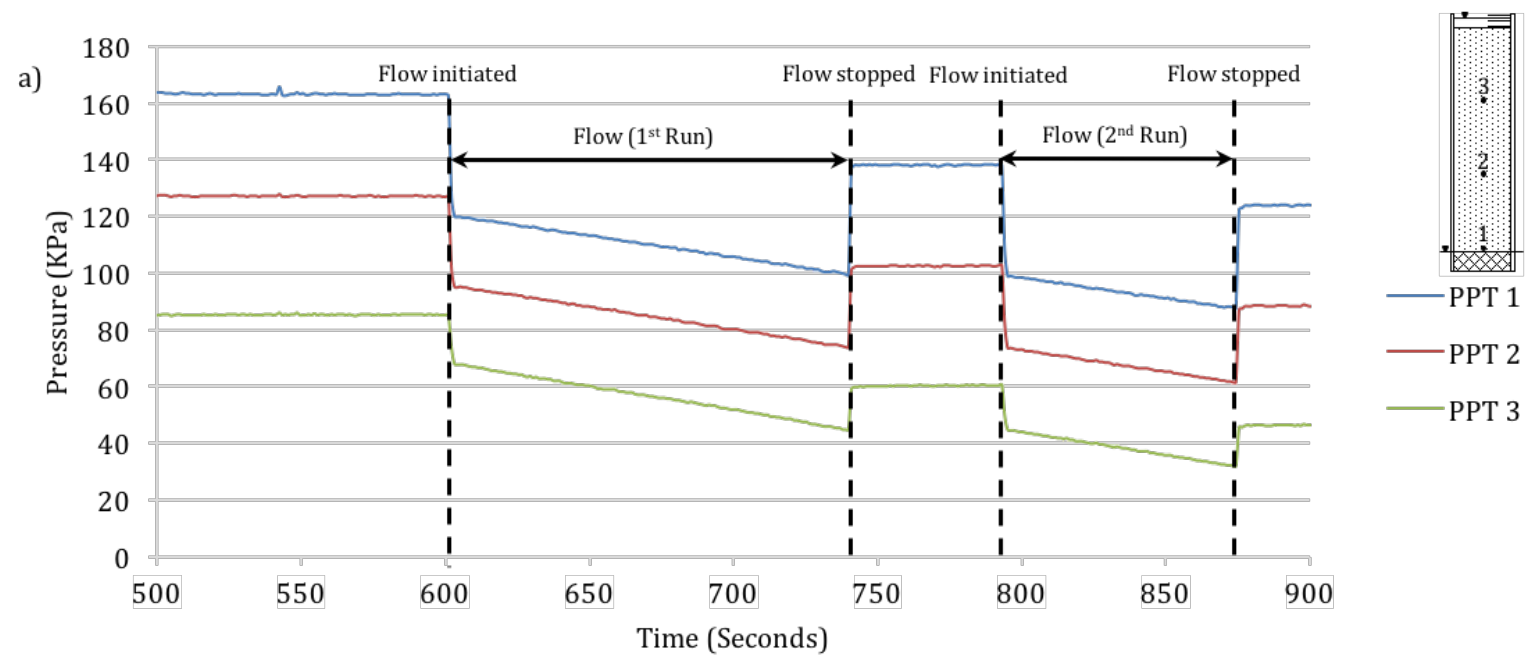

b)
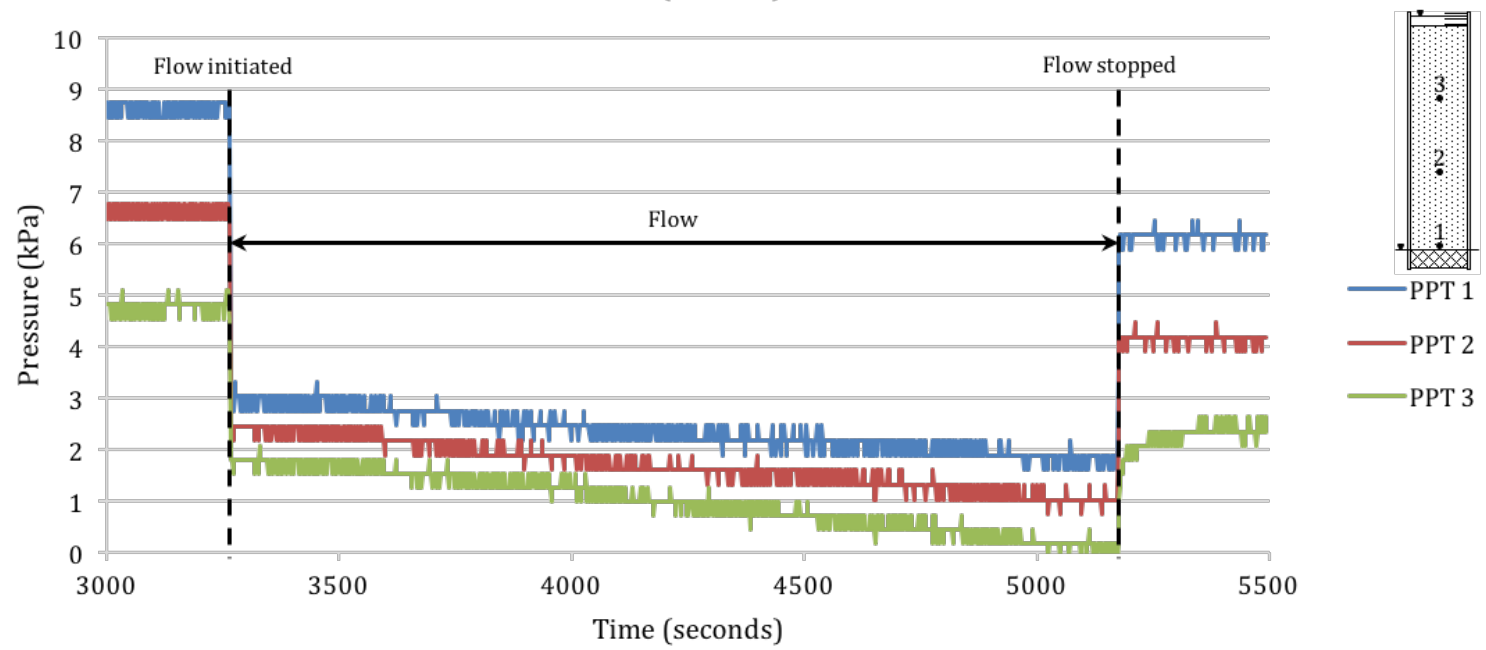

Figure 2. a) Recorded pore pressure data at 23g, and b) Recorded pore pressure data at $1 \mathrm{~g}$.

In the $23 \mathrm{~g}$ test, the change in total head $(\Delta H)$ between each PPT in the model is extracted from the pore pressure values and presented in

Table 2. A maximum $\Delta H$ is calculated between PPT 3 and PPT 1 , while the minimum $\Delta H$ is calculated between PPT 1 and PPT 2, indicating that the $\Delta H$ increases with increasing PPT separation distances.

Table 2. Calculated change in total head between each PPT at $23 \mathrm{~g}$.

\begin{tabular}{|c|c|c|c|c|c|c|c|c|}
\hline \multirow[b]{2}{*}{ PPT } & \multirow{2}{*}{$\begin{array}{c}\text { Elevation } \\
\text { (m) }\end{array}$} & \multicolumn{3}{|c|}{ Hydrostatic conditions } & \multicolumn{3}{|c|}{ Steady state flow established } & \multirow{2}{*}{$\begin{array}{c}\Delta H \\
(\mathrm{kPa})\end{array}$} \\
\hline & & $h_{p s}(\mathrm{kPa})$ & $H(\mathrm{kPa})$ & $h_{z}(\mathrm{kPa})$ & $h_{p f}(\mathrm{kPa})$ & $H_{f}(\mathrm{kPa})$ & $h_{z}(\mathrm{kPa})$ & \\
\hline 3 & 0.4 & 85 & 163.4 & 78.36 & 67.8 & 146.16 & 78.36 & 26.06 \\
\hline 2 & 0.2 & 127.1 & 163.4 & 36.34 & 95.2 & 131.54 & 36.34 & 14.62 \\
\hline 1 & 0 & 163.4 & 163.4 & 0 & 120.1 & 120.1 & 0 & 11.40 \\
\hline
\end{tabular}


In the $1 \mathrm{~g}$ test, determining the $\Delta H$ between each PPT as shown in Table 3 , required converting each PPTs pore pressures during steady state flow in Figure $2 b$ to pressure heads through the division by the unit weight of water and adding the respective PPT elevation. The maximum $\Delta H$ again occurred between PPT 1 and 3 , further illustrating that $\Delta H$ increases correspondingly with PPT separation. However, the calculated $\Delta H$ for both the lower and middle portions of the model are very similar and only differ by $0.0082 \mathrm{~m}$, with the lower portion of the model exhibiting a slightly larger $\Delta H$ and therefore showing that the $\Delta H$ decreases slightly with elevation.

Table 3. Calculated change in total head for each PPT at $1 \mathrm{~g}$.

\begin{tabular}{ccccccc}
\hline & & \multicolumn{5}{c}{ Steady state flow established } \\
\cline { 3 - 7 } PPT & Elevation $(\mathrm{m})$ & \multirow{2}{*}{$h_{p f}(\mathrm{kPa})$} & $H_{p f}(\mathrm{~m})$ & $H_{f}(\mathrm{~m})$ & $h_{p z}(\mathrm{~m})$ & $\Delta H(\mathrm{~m})$ \\
\hline 3 & & 1.81 & 0.1845 & 0.5845 & 0.4 & 0.2756 \\
2 & 0.4 & 2.46 & 0.2508 & 0.4508 & 0.2 & 0.1337 \\
1 & 0.2 & 3.03 & 0.3089 & 0.3089 & 0 & 0.1419 \\
\hline
\end{tabular}

When analysing the pore pressure data of both the $23 \mathrm{~g}$ and $1 \mathrm{~g}$ tests it becomes apparent that the pore pressures display a similar distribution in both tests. It should be noted that the pore pressures in the $1 \mathrm{~g}$ test provide lower values due to the lack of centrifugal force to drive flow, while for the $23 \mathrm{~g}$ test the increased acceleration represents a prototype sample height of $11.4 \mathrm{~m}$ and the corresponding pore pressure values. Regardless of the centrifugal force, all three PPTs respond rapidly in both tests with sharp pore pressures drops, indicating that the model is hydraulically well connected, most likely related to the model's hydraulic conductivity since finegrained sand is used in the model.

To assess the accuracy of the measured hydrostatic pore pressures in both the $23 \mathrm{~g}$ and $1 \mathrm{~g}$ tests, theoretical hydrostatic pressure heads are calculated and plotted according to the respective PPT elevations within the model, which indicate that initial hydrostatic head $\left(h_{p s}\right)$ increases with depth and correlate well with theoretical distributions as shown in Figure 3a and Figure 3c. This accuracy is further supported by the total initial head $\left(H_{s}\right)$, which is constant throughout the column for both the $23 \mathrm{~g}$ and $1 \mathrm{~g}$ tests as shown in Figure $3 \mathrm{~b}$ and Figure $3 \mathrm{~d}$, and therefore means that measured pore pressure values are accurate. 


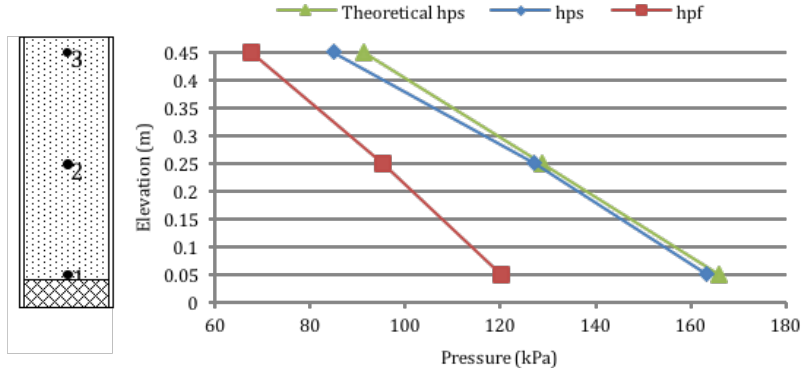

a)
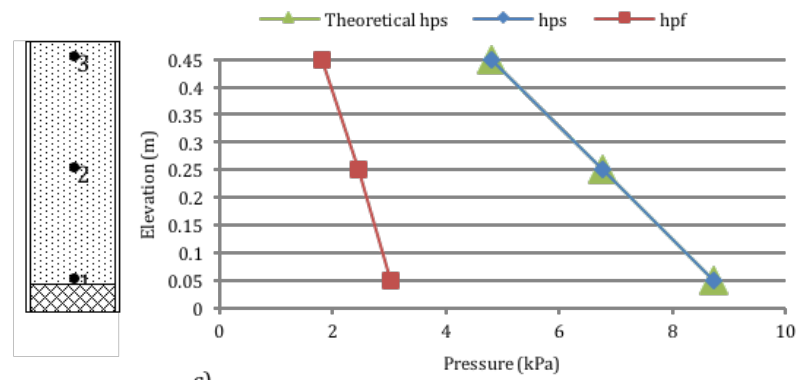

c)

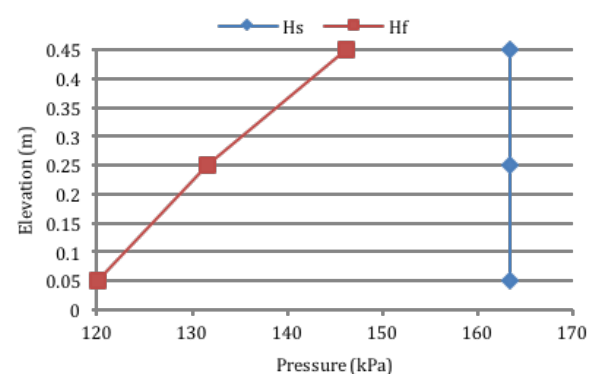

b)

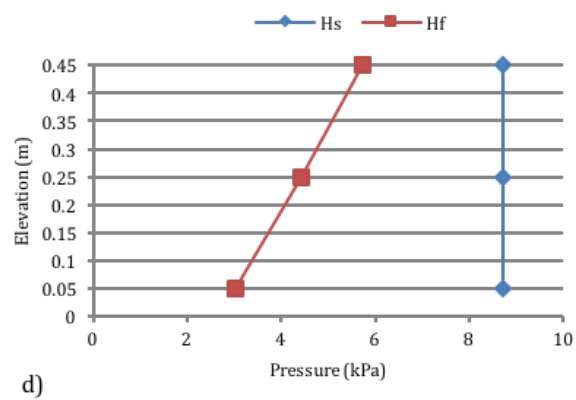

d)

Figure 3. Distribution of a) the calculated theoretical $h_{p s}$, measured $h_{p s}$ and $h_{p f}$, and b) $H_{s}$ and $H_{f}$ at $23 \mathrm{~g}$. Distribution of c) the calculated theoretical $h_{p s}$, measured $h_{p s}$ and $h_{p f}$, and d) $H_{s}$ and $H_{f}$ at $1 \mathrm{~g}$.

However, for both the $23 \mathrm{~g}$ and $1 \mathrm{~g}$ tests, the final hydrostatic head $\left(h_{p f}\right)$ increases with depth once flow is initiated, with the maximum and minimum values still at PPT 1 and 3, respectively. This measured response does not correlate to the expected theoretical response where the pore pressure at PPT 1 should decrease to atmospheric pressure when the solenoid valves are open, and indicate that the tests are not free draining and therefore not a true falling head test. This is due to the valves being flow constrictors, which caused the subsequent accumulation of pore pressures through length of the sample. Despite the constriction posed by the outlet valves, the final head $\left(H_{f}\right)$ for both the $23 \mathrm{~g}$ and $1 \mathrm{~g}$ tests decreases with depth and correlates to the expected theoretical response as shown in Figure $3 \mathrm{~b}$ and Figure 3d. Therefore, Bernoulli's law is satisfied and downward flow is maintained through the column.

\subsubsection{Model hydraulic conductivity}

The volumetric discharge $(Q)$ is calculated for each test and together with the calculated $\Delta H$, the $K$ values between each PPT for both acceleration levels are determined and presented in Table 4. The calculated average $K$ values for both the $23 \mathrm{~g}$ and $1 \mathrm{~g}$ test fall within the same order of magnitude. This indicates that the applied inertial acceleration in the centrifuge has a minimal effect of compression of the material at high accelerations. 
There are some differences between the $K$ values calculated for the two tests, whereby the $K$ value decreases with elevation for the $23 \mathrm{~g}$ test (PPT 1 to 2 , and PPT 2 to 3), while the $K$ value increases with elevation for the $1 \mathrm{~g}$ test (PPT 1 to 2, and PPT 2 and 3).

Table 4. Calculated difference in $K$-values $(\mathrm{m} / \mathrm{s})$ between the $23 \mathrm{~g}$ and $1 \mathrm{~g}$ tests.

\begin{tabular}{cccc}
\hline PPT & $K_{23 \mathrm{~g}}$ & $K_{1 \mathrm{~g}}$ & $K_{1 \mathrm{~g}} / K_{23 \mathrm{~g}}$ \\
\hline 1 to 2 & $1.716 \mathrm{E}-04$ & $1.822 \mathrm{E}-04$ & 1.062 \\
2 to 3 & $1.343 \mathrm{E}-04$ & $1.933 \mathrm{E}-04$ & 1.440 \\
1 to 3 & $1.507 \mathrm{E}-04$ & $1.876 \mathrm{E}-04$ & 1.245 \\
\hline Average & $1.522 \mathrm{E}-04$ & $1.877 \mathrm{E}-04$ & 1.233 \\
\hline
\end{tabular}

The calculated hydraulic conductivity calculated using the pore pressures for both the $23 \mathrm{~g}$ and $1 \mathrm{~g}$ tests falls within the typical range of $1.00 \times 10^{-5} \mathrm{~m} / \mathrm{s}$ and $1.00 \times 10^{-3} \mathrm{~m} / \mathrm{s}$ for a fine-grained sand (Fetter 2001; Knappett and Craig 2012), thereby providing a promising and accurate estimate of hydraulic conductivity. When comparing the time taken for the head to fall by $0.24 \mathrm{~m}$ in each test, it is apparent that the $23 \mathrm{~g}$ test took significantly less time than the $1 \mathrm{~g}$ test. This results in seepage velocity that is substantially larger in the centrifuge with hydraulic conductivity scaling by a factor of $N$ as concluded by Singh and Gupta (2002). However, the hydraulic conductivities calculated using the measured pore pressures at $1 \mathrm{~g}$ and $23 \mathrm{~g}$ only differ by the small margins, as shown in Table 4, where the $1 \mathrm{~g}$ hydraulic conductivity is only 1.233 times greater than that of the $23 \mathrm{~g}$ and can be attributed to a slight densification of the sample in the centrifuge, which lowers the conductivity in the centrifuge. Nevertheless, the measured difference is insignificant in terms of seepage and contradicts Singh and Gupta (2002). This is further supported by the hydrostatic pore pressures $\left(h_{p s}\right)$ of the $1 \mathrm{~g}$ and $23 \mathrm{~g}$ tests, where dividing hydrostatic pore pressure of the $23 \mathrm{~g}$ test with the average centrifugal acceleration provides almost identical pressures compared to the $1 \mathrm{~g}$ test as shown in Table 5:

Table 5. Comparison of the measured hydrostatic pore pressures at $1 \mathrm{~g}$ and $23 \mathrm{~g}$

\begin{tabular}{ccccc}
\hline PPT & Elevation $(\mathrm{m})$ & $h_{p s}$ at $1 \mathrm{~g}(\mathrm{kPa})$ & $h_{p s}$ at $23 \mathrm{~g}(\mathrm{kPa})$ & $H_{p s}$ at $23 \mathrm{~g} / N_{r}(\mathrm{kPa})$ \\
\hline 1 & 0 & 8.732 & 163.4 & 8.600 \\
2 & 0.2 & 6.485 & 127.1 & 6.689 \\
3 & 0.4 & 4.804 & 85 & 4.474 \\
\hline
\end{tabular}

The results from this experiment demonstrate that the calculated hydraulic conductivities for the $1 \mathrm{~g}$ and $23 \mathrm{~g}$ tests and the reported hydraulic conductivities are in close accordance, proving (as mentioned by Robinson 2002) that hydraulic conductivity is a material parameter that is unaltered in the centrifuge, assuming that the material does not compress. A Reynolds number of $2.249 \times 10^{-3}$ is calculated for the $23 \mathrm{~g}$ test, indicating that laminar flow conditions prevailed during centrifugation, hence Darcy's law is valid in the experiment. Therefore, in order to 
scale seepage velocity appropriately, the hydraulic gradient must be scaled by a factor of $N$ and not hydraulic conductivity.

\section{EXPERIMENT 2: UNSATURATED TRANSVERSE HYDRODYNAMIC DISPERSION}

\subsection{Model preparation and test procedure}

The model shown in Figure 4 is used to explore hydrodynamic dispersion in a geotechnical centrifuge. This model is constructed in a strongbox with a window, where an inner-spacer plate is placed inside to reduce the total base area to $150 \times 600 \mathrm{~mm}$. A $5 \times 5 \mathrm{~mm}$ grid is placed against the window and identical dry sand used in hydraulic conductivity model is pluviated from a height of $0.75 \mathrm{~m}$ to ensure a constant density range between $1600 \mathrm{~kg} / \mathrm{m}^{3}$ and $1700 \mathrm{~kg} / \mathrm{m}^{3}$. A small container with a $2 \mathrm{~mm}$ wide slit down the centre is lined with a geotextile and placed in the centre, on top of the soil profile where it is connected to an inlet pipe leading from $4 l$ water storage tank with a solenoid valve and an outlet pipe is installed in the base of the model.

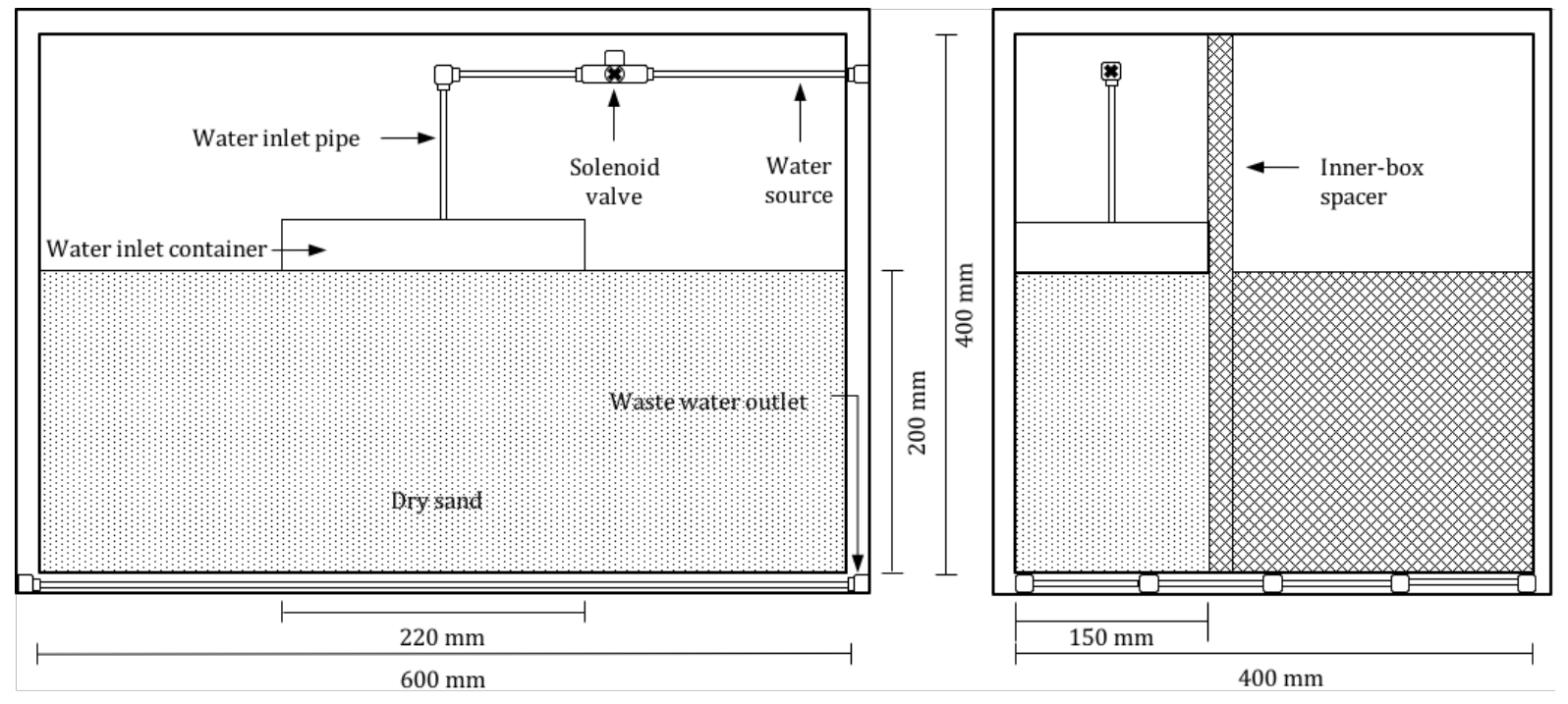

Figure 4. Test set-up for experiment 2: Hydrodynamic dispersion.

Six tests are performed at acceleration levels of $1 \mathrm{~g}, 2 \mathrm{~g}, 5 \mathrm{~g}, 10 \mathrm{~g}, 20 \mathrm{~g}$ and $40 \mathrm{~g}$ respectively. In each test the solenoid valve is opened and the storage tank is allowed to drain freely through the soil profile. The dispersion plume evolution is visually captured by time interval photographs and the total extent of hydrodynamic 
dispersion is recorded against the grid at reference depths of $50 \mathrm{~mm}, 100 \mathrm{~mm}$ and $150 \mathrm{~mm}$ below the soil surface from the centreline to the right hand side of the model.

\subsection{Results and discussion}

A summary of the results is provided in Table 6, accompanied by Figure 5, depicting the visual progression of the plume in each test, at different stages of development. A number of assumptions are imposed on the results, which include: (i) the soil is homogeneous and isotropic; (ii) the water properties are not affected by the addition of food colourant; (iii) laminar flow conditions occur throughout the experiment; (iv) no rotational effects occur; (v) and the principle axes of velocity and gravitational acceleration coincide resulting in transverse hydrodynamic dispersion occurring perpendicular to this axes.

Table 6. Summary of transverse hydrodynamic dispersion experiments

\begin{tabular}{cccccccc}
\hline & & & & \multicolumn{3}{c}{ Dispersion distance at reference depth $(\mathrm{mm})$} \\
\cline { 6 - 8 } $\begin{array}{c}\text { g- } \\
\text { level }\end{array}$ & $\begin{array}{c}\text { Weight } \\
\text { before }(\mathrm{kg})\end{array}$ & $\begin{array}{c}\text { Weight } \\
\text { after }(\mathrm{kg})\end{array}$ & $\begin{array}{c}\text { Height of } \\
\text { soil }(\mathrm{mm})\end{array}$ & $\begin{array}{c}\text { Density } \\
\left(\mathrm{kg} / \mathrm{m}^{3}\right)\end{array}$ & $50 \mathrm{~mm}$ & $100 \mathrm{~mm}$ & $150 \mathrm{~mm}$ \\
\hline $\mathbf{1}$ & 231.0 & 263.0 & 210 & 1693.12 & 170 & 145 & 90 \\
$\mathbf{2}$ & 232.0 & 263.0 & 210 & 1640.21 & $120^{*}$ & $110^{*}$ & $70^{*}$ \\
$\mathbf{5}$ & 232.0 & 261.0 & 200 & 1611.11 & $150^{*}$ & $140^{*}$ & $110^{*}$ \\
$\mathbf{1 0}$ & 232.0 & 262.0 & 200 & 1666.67 & 110 & 120 & 120 \\
$\mathbf{2 0}$ & 232.0 & 261.0 & 200 & 1611.11 & 50 & 65 & 75 \\
$\mathbf{4 0}$ & 233.0 & 263.0 & 200 & 1666.67 & 50 & 55 & 60 \\
\hline
\end{tabular}

*Asymmetrical dispersion plume

In addition to these assumptions, a boundary error occurred in the $40 \mathrm{~g}$ experiment where a water release problem resulted in two dispersion plumes forming in the model. However, the results do not seem to be compromised, as there is minimal interference between the two plumes allowing the dispersion readings to still be recorded. 


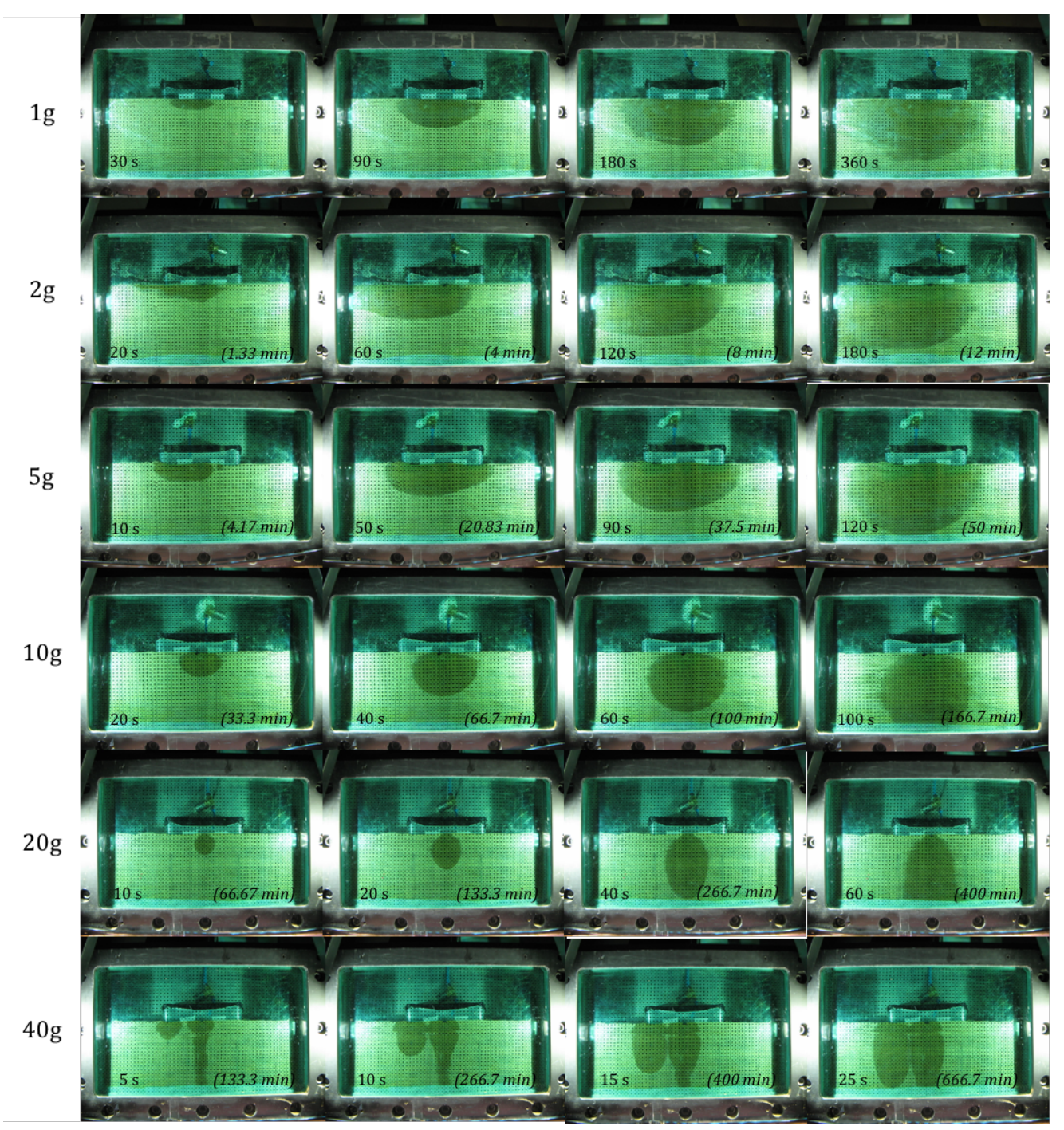

Figure 5. Photographic sequence of the dispersion tests ( $5 \mathrm{~mm} \times 5 \mathrm{~mm}$ grid). Value sin parenthesis refer to prototype time.

\subsubsection{Dispersion plume evolution}

At the start of each experiment, the dispersion plume expands in a circular fashion as the flow paths are forced to flow around the soil grains. From this initial stage, depending on the level of gravitational acceleration, four different plume progression and shape scenarios occur as shown in Figure 6, and are described as follows:

- Scenario 1: The plume continues to expand in a circular fashion in an attempt to saturate as much of the soil as possible, resulting in a ever increasing semi-circular wetting front. This indicates that lateral movement in the soil is the dominant direction of flow until a fully saturated column is formed and downward progression occurs. 
- Scenario 2: Evident in the $2 \mathrm{~g}$ and to a lesser extent in the $5 \mathrm{~g}$ experiments, is the progression of the plume in an asymmetrical shape. This progression occurs due to the resultant acceleration level not acting perpendicularly downwards from the soil surface but rather at an angle dependent on the direction and magnitude of the two gravitational acceleration components. This provides results that are unreliable, however, experiments performed at such low acceleration levels are impractical as upon scaling of model dimensions, prototype conditions of $1 \mathrm{~m}$ will be modelled. Therefore, experiments regarding seepage problems in a geotechnical centrifuge should be conducted at gravitational acceleration levels of $10 \mathrm{~g}$ or higher.

- Scenario 3: Occurs approximately between acceleration levels of $10 \mathrm{~g}$ and $20 \mathrm{~g}$, and is the progression of the dispersion plume with a reduced semi-circular wetting front. Initially the plume begins to disperse, but is then forced to maintain its shape as it progresses through soil until contacting the bottom boundary, where a boundary effect causes the fluid to pond and spread laterally, resulting in a final shape of a bell.

- Scenario 4: Occurs at higher accelerations and is the progression of the plume as a saturated column with a semi-circular end. The higher acceleration levels inhibit transverse dispersion as evident from the maintained fixed shape during progression through the soil, which result ultimately in a column shape as seepage occurs fast enough to stop spreading at the boundary.

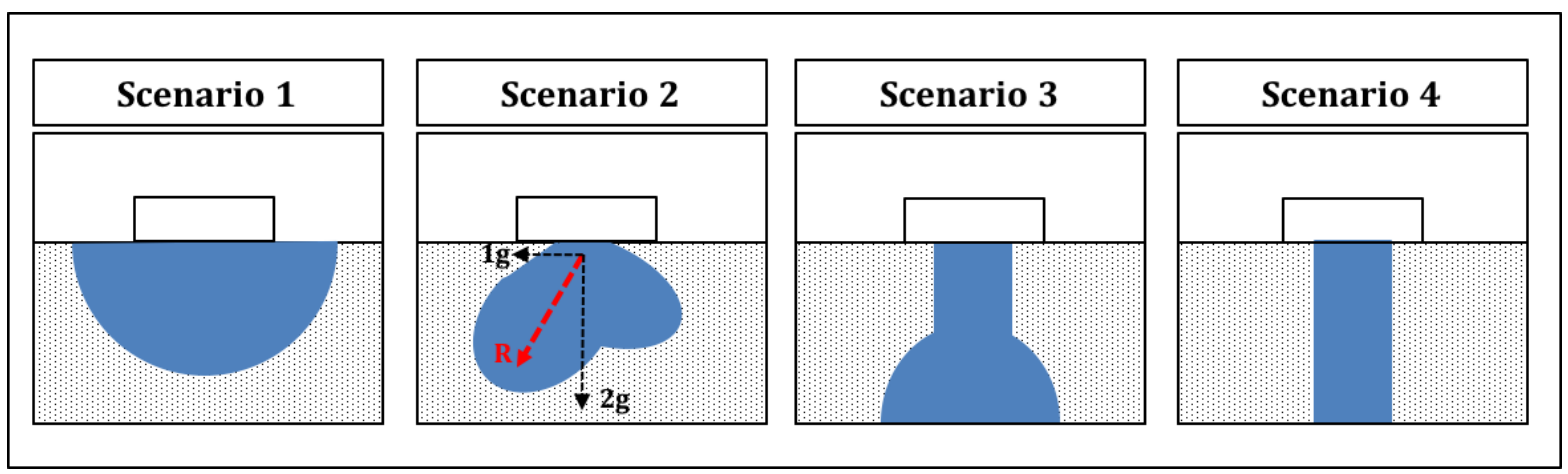

Figure 6. Scenarios of plume shape.

\subsubsection{Dispersion measurements}

The final transverse dispersion readings at reference depths of $50 \mathrm{~mm}, 100 \mathrm{~mm}$ and $150 \mathrm{~mm}$ are represented by the blue, red and green lines respectively in Figure 7, where the results for the $2 \mathrm{~g}$ test have been omitted due to the resultant gravitational force providing unreliable results. 


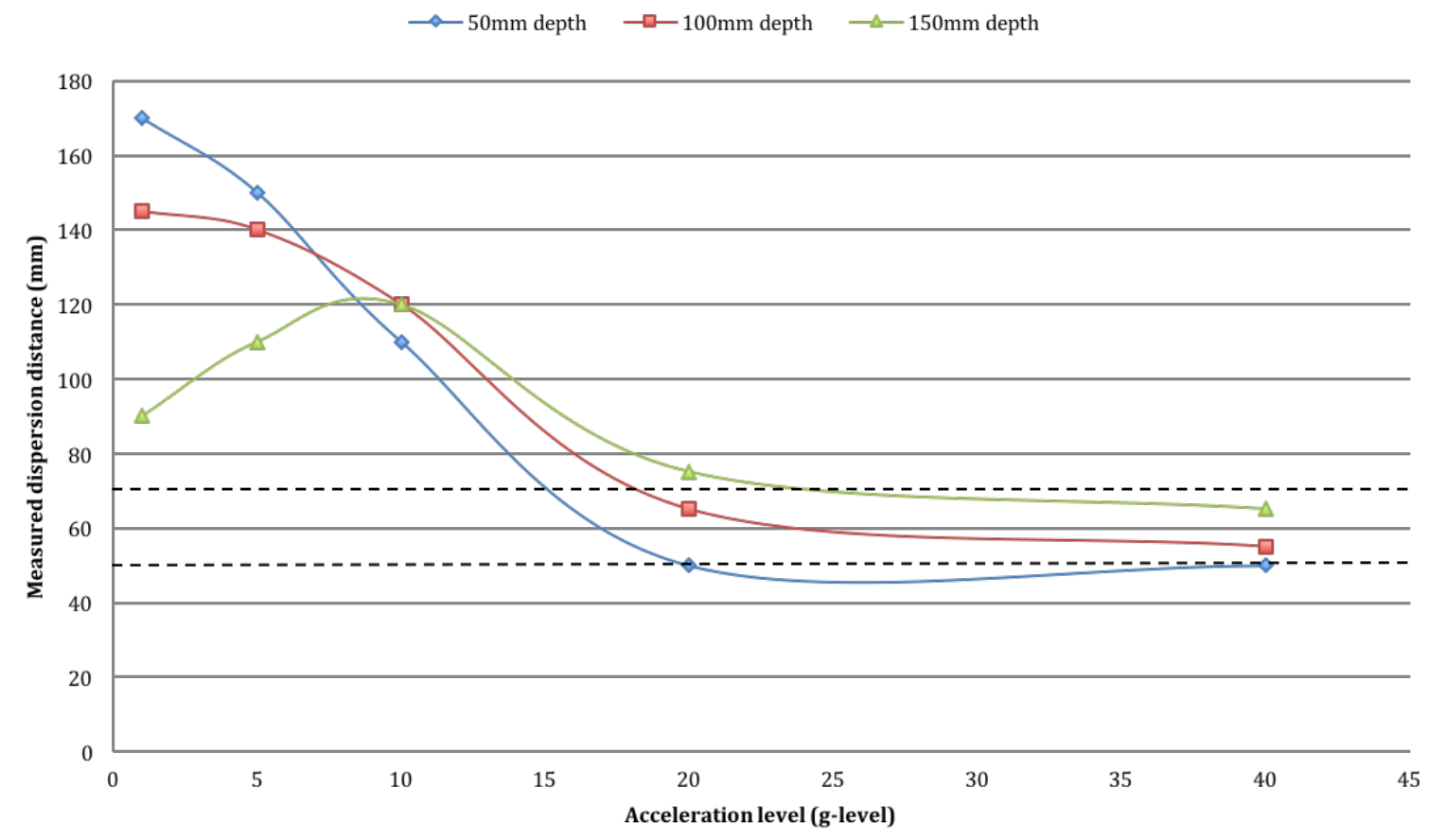

Figure 7. Combined fine-grained reference depths dispersion distances at different acceleration levels

At low gravitational acceleration levels (i.e. below 10g), there is a large range of dispersion values, with the largest value occurring at shallower depths. This implies that at low gravitational acceleration levels, diffusion briefly dominates the driving force until a saturation fringe is developed and the gravitational force then dominates. Increasing the gravitational acceleration levels results in the dispersion distances converging to a range of 115 to $120 \mathrm{~mm}$ during the $10 \mathrm{~g}$ experiment, with the lowest value now occurring at the shallowest depth. The increased gravitational acceleration level inhibits lateral dispersion and forces the dispersion plume progression as a fixed shape within the soil profile.

Increasing the gravitational acceleration levels further maintains a fixed shape but causes a further reduction in dispersion distances, which now range between 50 and $75 \mathrm{~mm}$ for the $20 \mathrm{~g}$ experiment. Further increasing the gravitational acceleration levels results in only a slight decrease in the dispersion distance, which now range between 50 and $65 \mathrm{~mm}$ for the $40 \mathrm{~g}$ experiment. This indicates that at approximately $20 \mathrm{~g}$ acceleration levels, a threshold dispersion distance ranging between 50 and $70 \mathrm{~mm}$ is obtained and no further decrease in dispersion readings will occur with any further increase in gravitational acceleration levels.

\subsubsection{Prototype conditions}


To evaluate the validity of scaling dispersion in a geotechnical centrifuge, the reference depths are scaled using a factor of 1:N and the dispersion distances for each of the respective reference depths are scaled using scaling factor of 1:N, 1: $N^{0.9}, 1: N^{0.8}, 1: N^{0.75}$ and $1: N^{0.5}$ as proposed by Hensley and Randolph (1994). A scaling factor of 1:N produces the most amount of scatter in the data and results in large increases in dispersion distances with increased prototype depths. This is unlike the $1: N^{0.5}$ scaling factor, which resulted in a lowest amount of scatter in the data but contained the weakest correlation of all the scaling factors. However, using scaling factors ranging between $1: N^{0.75}$ and $1: N^{0.9}$ provides data with a minimal degree of scatter while maintaining a meaningful relationship between dispersion distance and prototype depth

Analysis of the scaled data revealed that a linear relationship exhibits low correlation and over-estimates dispersion distances, while a polynomial and logarithmic relationship provides stronger correlation and better fit for the data. Extrapolation of the polynomial relationship, shown in Figure 8a, indicates that with an increase in the depth there is initially an increase in scaled dispersion distance followed by a rapid decrease until $10 \mathrm{~m}$ prototype depth where zero dispersion occurs. This relationship indicates a scenario 3 plume and could represent a scenario where a finite amount of fluid is added to the system or alternatively, an insufficient amount of time is allowed to pass for the plume to migrate fully through the soil. Extrapolating the logarithmic relationship on the other hand indicates an ever-increasing dispersion distance with depth and could possibly represent a steady state flow with an infinite amount of source fluid scenario as shown in Figure 8b. 


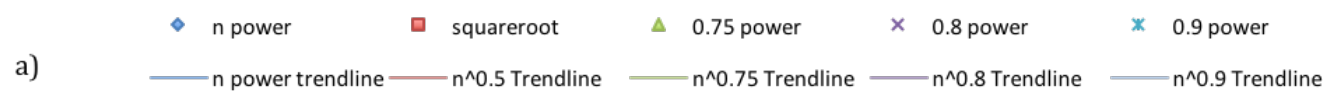

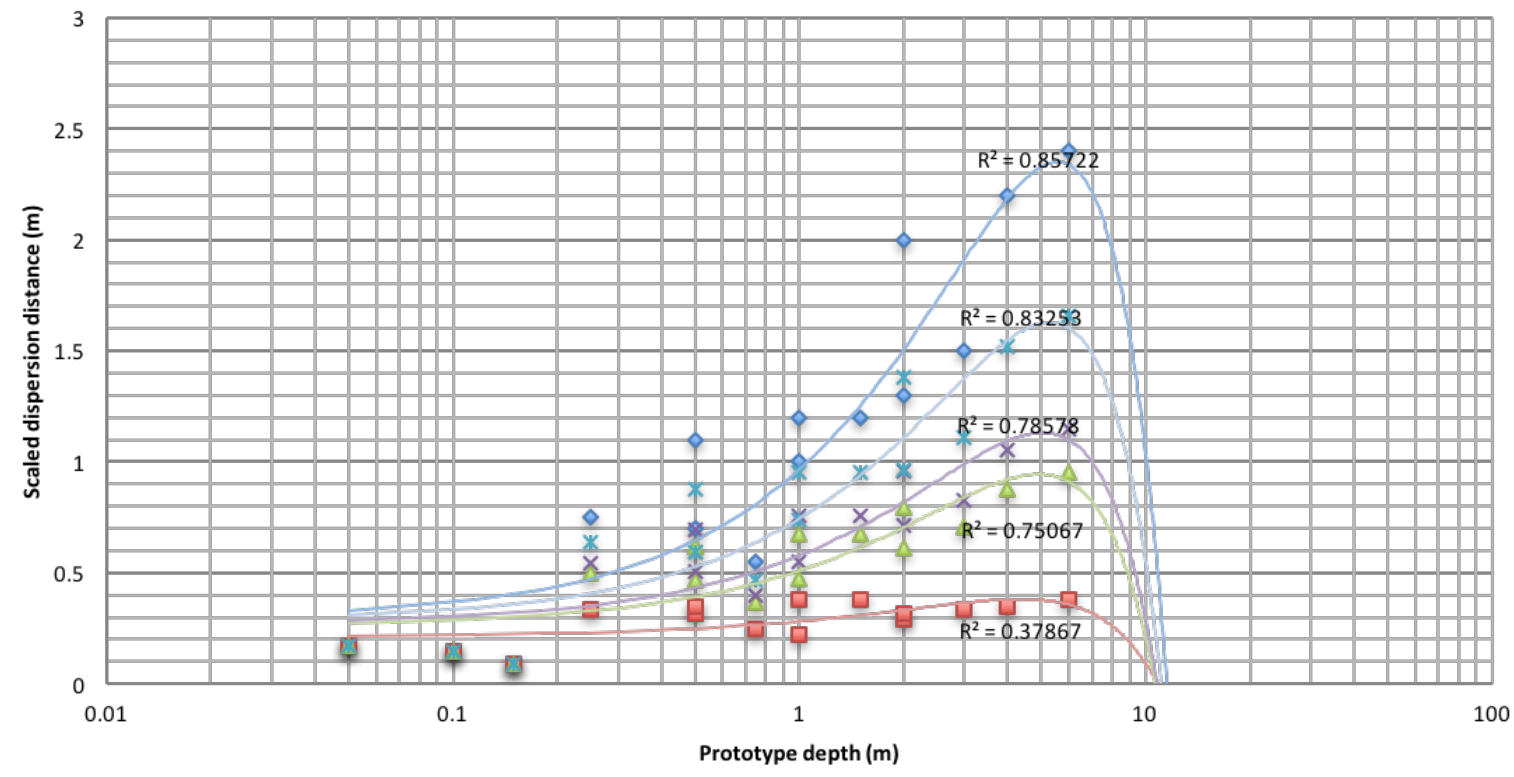

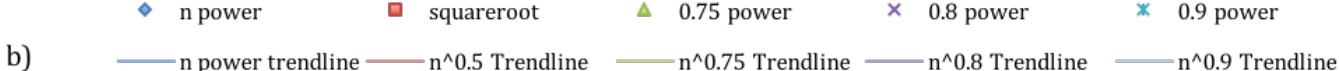

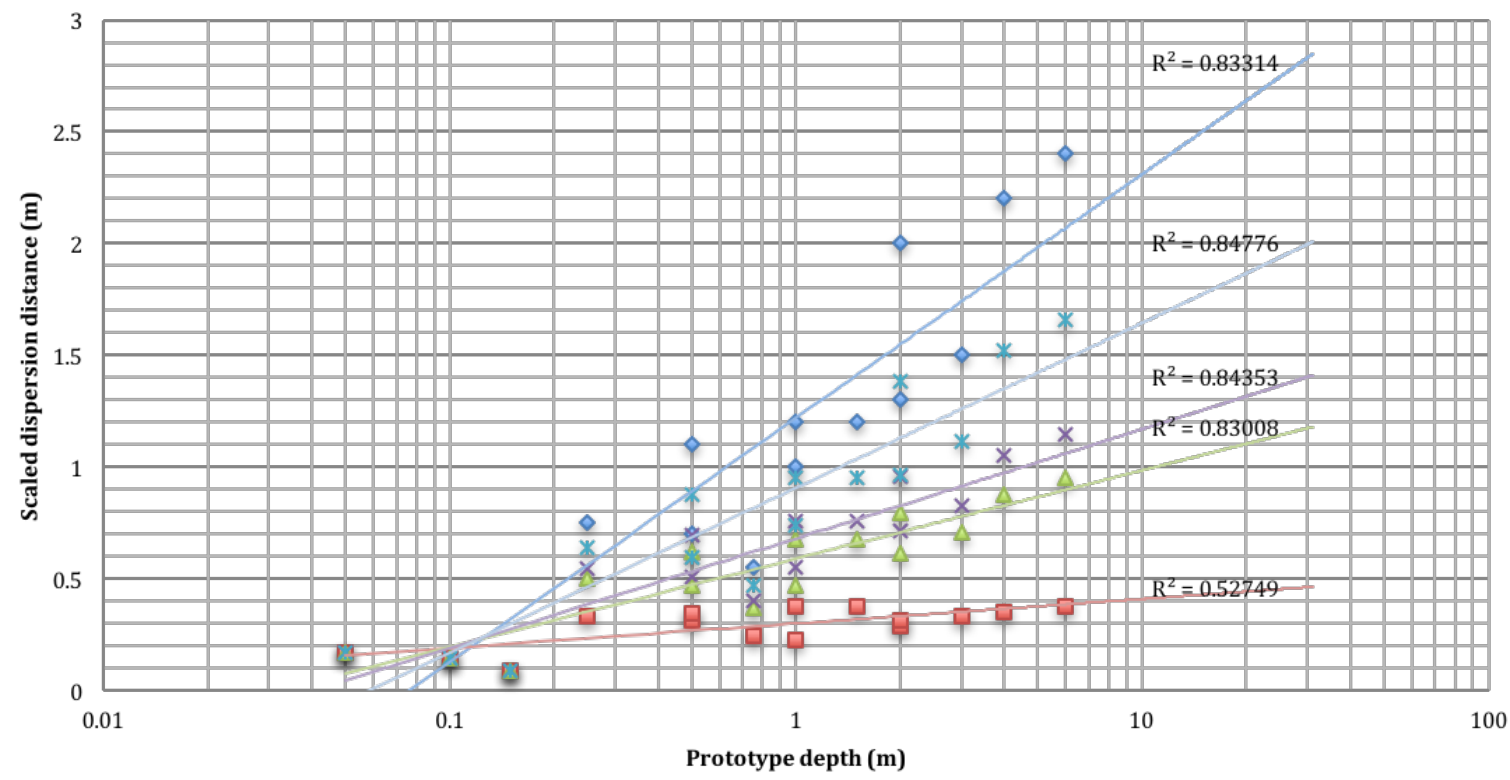

Figure 8. a) Semi-logarithmic graph of scaled prototype conditions with polynomial relationship, and b) Semilogarithmic graph of scaled prototype conditions with logarithmic relationship.

To inspect if the calculated prototype conditions are a true representation of natural conditions, the dispersion distances for the logarithmic relationship using scaling factors ranging between $N^{0.75}$ to $N^{0.9}$ is analysed and provides a $30 \mathrm{~m}$ deep dispersion plume with a total plume width of $2.4-4 \mathrm{~m}$. If the plume depth is regarded as 
longitudinal dispersion and the plume width regarded as transverse dispersion, the ratio of transverse dispersion $\left(D_{T}\right)$ and longitudinal dispersion $\left(D_{L}\right)$ range for these extrapolated values is shown in Equation 1.

$$
\frac{2}{25}<\frac{D_{T}}{D_{L}}<\frac{2}{15}
$$

This estimated ratio is approximately $1 / 10$, which is the common ratio assumed between the two coefficients in groundwater modelling (e.g. Aziz et al. 2000; Delleur 2006; Wiedemeier et al. 1996), indicating the geotechnical centrifuge is viable experimental method to determine hydrodynamic dispersion.

\section{EXPERIMENT 3: UNSATURATED DISCRETE FRACTURE FLOW}

\subsection{Model preparation and test procedure}

The vertical fracture model test is performed on a fracture measuring $100 \mathrm{~mm}$ height $\mathrm{x} 110 \mathrm{~mm}$ width, with a constant aperture of $1 \mathrm{~mm}$ as shown in Figure 9a. Assuming saturated conditions and that the fracture aperture is a microscopic length that does not scale, the fracture replica is therefore characterised by a hydraulic conductivity $\left(K_{f}\right)$ of $9.18 \times 10^{-1} \mathrm{~m} / \mathrm{s}$. Model preparation begins with the placement of a camera and metal support columns at the base of the model. Two bent L-section acrylic Plexiglas sheets measuring $299.5 \mathrm{~mm}$ long are placed in a strongbox with a total length of $600 \mathrm{~mm}$. This allowed a constant aperture of $1 \mathrm{~mm}$ to be maintained for the fracture between the acrylic Plexiglas sheets. A back plate is then installed in the strongbox and three screw jacks confine the fracture against the window and back plate where a water inlet container is constructed around the fracture. Foam sealant tape is placed around the interior and exterior perimeter of the water inlet container to maintain a watertight seal where potassium permanganate crystals are scattered to colour the water. A water inlet pipe with a solenoid valve is installed above the fracture and an outlet is installed at the base of the model. 
a)

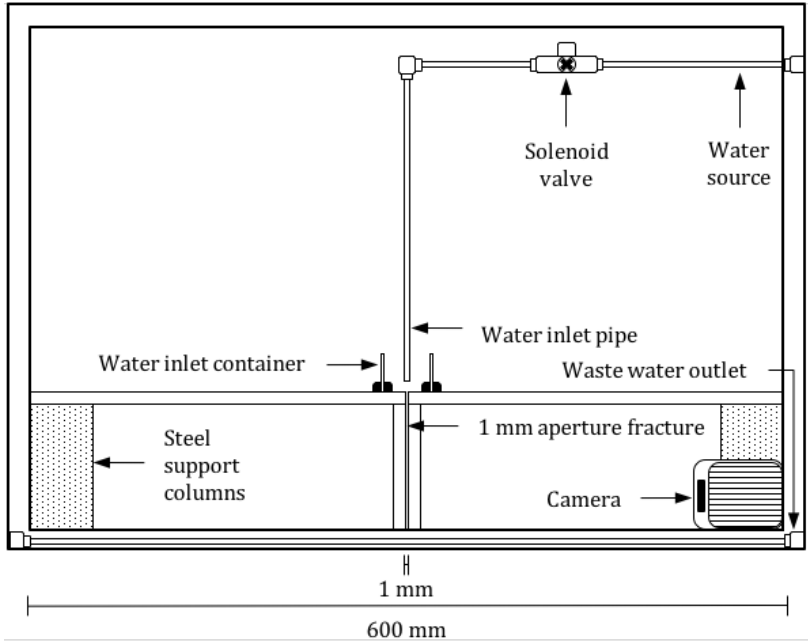

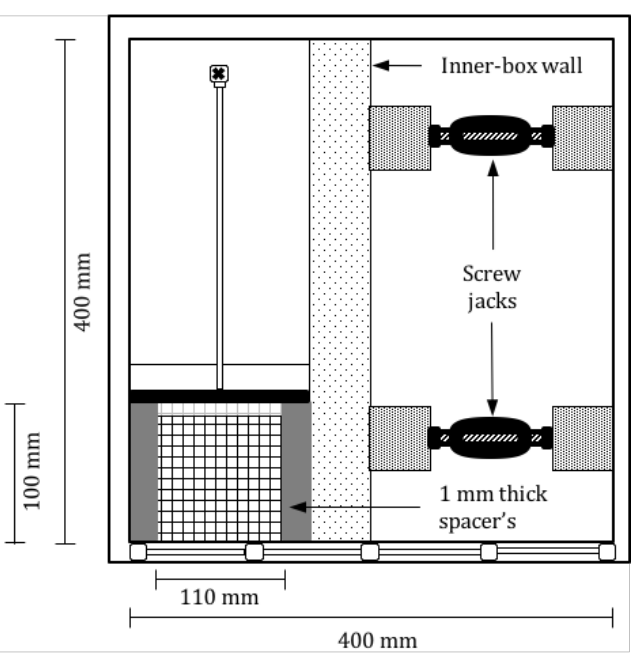

$400 \mathrm{~mm}$

b)
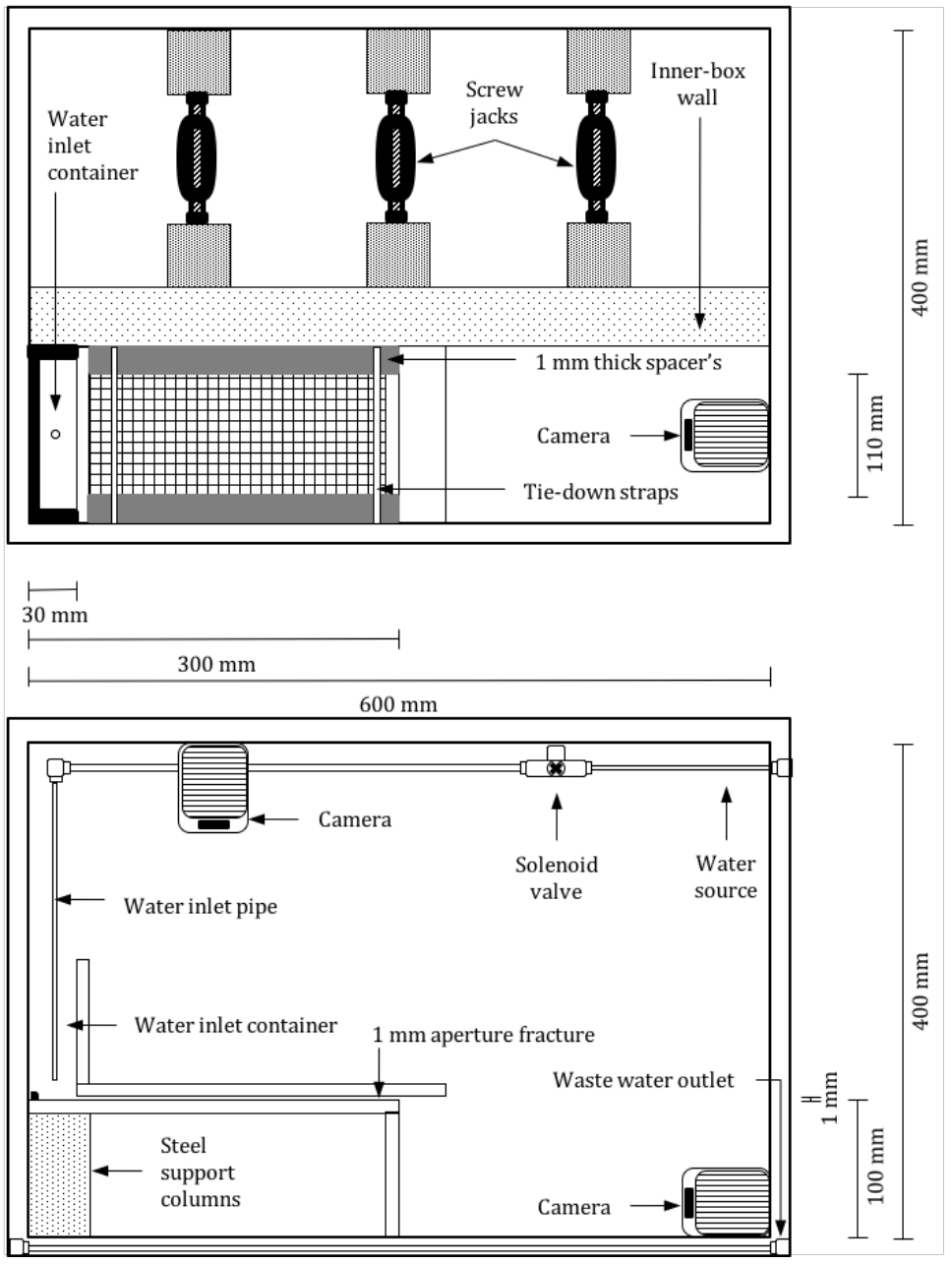

Figure 9. Model set up for the: a) vertical fracture flow test (cross-sectional view is shown on the left, and side view - observing the vertical fracture perpendicularly- shown on the right); and b) horizontal fracture flow test (plan view - observing the horizontal fracture perpendicularly - shown on the top, and cross-sectional view shown on the bottom). 
The horizontal fracture model test is performed on a horizontal fracture measuring $270 \mathrm{~mm}$ length $\mathrm{x} 110 \mathrm{~mm}$ width, with a constant aperture of $1 \mathrm{~mm}$, maintained by spacers. The hydraulic conductivity of the fracture is the same as reported in the vertical experimental set-up. The model is constructed using the same two L-section acrylic Plexiglas sheets, with one being slightly offset and inverted on top to allow for an inlet area as illustrated in Figure 9b. A water inlet container is constructed over this area by jacking the back plate, while sealing the interior and exterior perimeter with foam sealant to maintain a watertight seal, where potassium permanganate crystals are scattered to colour the water. A camera is placed on an overhead bracket above the horizontal fracture, while a second camera is placed on the right base of the model. A water inlet pipe with a solenoid valve is installed above the container while an outlet pipe is installed at the base of the model.

The completed model is accelerated to $20 \mathrm{~g}$ and tested under intermittent and continuous seepage conditions. For intermittent seepage tests, the solenoid valve is opened and influx is introduced as individual droplets for 3 minutes (20 hours, at prototype scale) at approximately $0.6 \mathrm{l} / \mathrm{hr},(12 \mathrm{l} / \mathrm{hr})$. The centrifuge is then stopped, the model dismantled, dried, and then reassembled for the continuous seepage test. The continuous seepage in the fracture consists of opening the solenoid valve and allowing an initial influx of $20 \mathrm{l} / \mathrm{hr}(400 \mathrm{l} / \mathrm{hr})$ into the model. This is followed by 1 -minute (6.67 hours) interval stepped influx increases, where an additional $201 / \mathrm{h}$ is added to the current flux until a total constant flux of $100 \mathrm{l} / \mathrm{h}(2000 \mathrm{l} / \mathrm{hr})$ is obtained for 1 minute. The water is then closed and the system drains for an additional minute before repeating the same stepped flux procedure stated above, but following shortened time intervals of 30 seconds (3.33 hours) between increases. The flow rate is manually observed in the centrifuge control room by a flow meter. During high flow influx intervals $(>601 / \mathrm{hr})$ cavitation occurs in the inlet pipes, whereby flow ceases temporarily causing a backpressure in the pipes and results in excess influxes being delivered to the model during re-stabilisation. Therefore, constant flow is not always achieved at these intervals, and although all the influxes results are presented, the discussion generally excludes the results of the intervals greater than $40 \mathrm{l} / \mathrm{hr}$.

\subsection{Results and discussion}

The following flow mechanisms were observed in the vertical fracture for both the intermittent and continuous flow tests, and are presented in Figure 10:

A. Invasion of a $0.42 \mathrm{~mm}(8 \mathrm{~mm})$ wide continuous rivulet, forming in approximately 0.1 seconds (40 seconds) through the length of the vertical fracture (Figure 10A-i to ii) over $90 \mathrm{~mm}(1.8 \mathrm{~m})$, during 
initial introduction of water in the intermittent flow test. A discontinuous path of discrete sliding droplets (Figure 10A-iii) forms adjacent to the initial rivulet, with an average width of $1 \mathrm{~mm}(20 \mathrm{~mm})$ and travel at approximately $150 \mathrm{~mm} / \mathrm{s}(7.5 \mathrm{~mm} / \mathrm{s})$.

B. A continuous rivulet, which does not extend the entire length of the vertical fracture, and at a length of approximately $20 \mathrm{~mm}$ becomes discontinuous where sliding droplets develop and detach intermittently. In this instance, there is not a sufficient volume of water to establish a continuous rivulet, and therefore discrete droplets break off from the rivulets when the weight of the drop is greater than the surface tension, resulting in static droplets occurring within the fracture once the rivulet snaps.

C. Flow switching of continuous rivulets occur due to meandering rivulets that oscillate, which leads to cessation of previous flow paths, and amalgamations with exiting flow paths, during the continuous flow tests. The rivulets are approximately 0.5 to $1 \mathrm{~mm}(10-20 \mathrm{~mm})$ wide and meander the entire length of the fracture. Furthermore, the amalgamation during the flow switches are often dictated by the position of static droplets scattered throughout the fracture.

D. Two populations of oscillating rivulets appear to cross-cut one another without influencing the observed flow. This highlights that rivulets do not form spanning liquid bridges constrained between both fracture walls but rather indicates flow occurs on opposing walls as continuous rivulets within the fracture. This mechanism is further conceptualised in Figure 10D-iv; by a cross-sectional top-view sketch through the vertical fracture.

E. Throughout the test intervals, preferential flow paths, with oscillating rivulets, give way to a curtain flow at higher influxes (shaded portions in Figure 10E), but never fully saturates the width of the fracture. At $20 \mathrm{l} / \mathrm{hr}(400 \mathrm{l} / \mathrm{hr})$, the preferential flow paths formed by the continuous rivulets saturate approximately $10 \%$ of the width of the fracture. This increases to $25 \%$ width area being saturated at 40 1/hr $(800 \mathrm{l} / \mathrm{hr})$; to $50 \%$ at $60 \mathrm{l} / \mathrm{hr}(1200 \mathrm{l} / \mathrm{hr})$; and $70 \%$ at $80 \mathrm{l} / \mathrm{hr}(1600 \mathrm{l} / \mathrm{hr})$, with full saturation not being achieved at $100 \mathrm{l} / \mathrm{hr}(2000 \mathrm{l} / \mathrm{hr})$. 


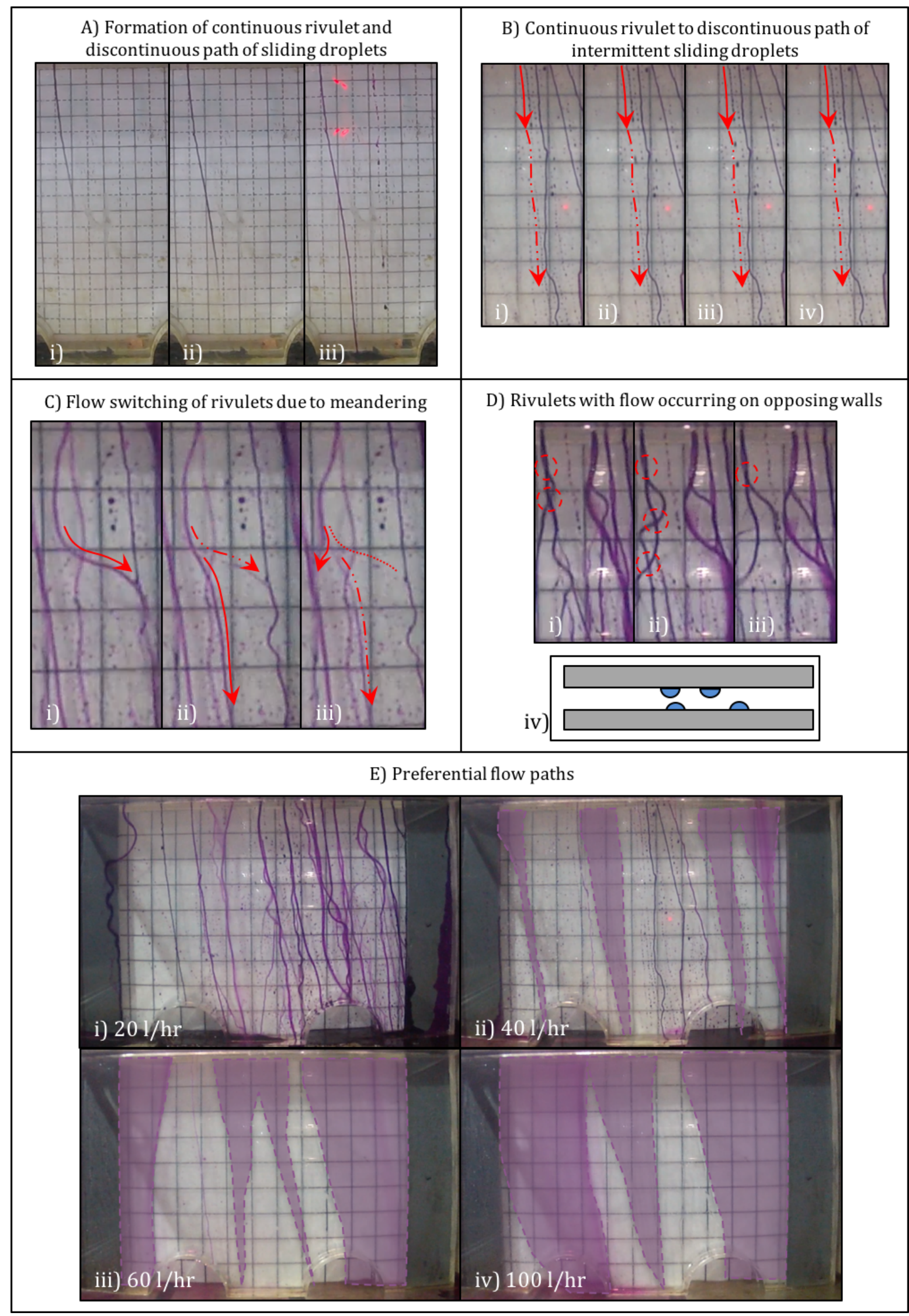

Figure 10. Flow mechanisms observed in the vertical fracture (A: $5 \mathrm{~mm}$ x $5 \mathrm{~mm}$ grid; B to E: $10 \mathrm{~mm} \times 10 \mathrm{~mm}$ grid). 
The following observations are seen in the horizontal fracture, and the vertical outlet wall, for both the intermittent (Figure 11) and continuous flow (Figure 12) tests:

- During the intermittent seepage test the wetting front is seen initially invading the horizontal fracture as a circular wetting front as shown in Figure 11, which eventually contacts the spacer. This boundary seems to act as a preferential flow path for the wetting front as it progresses through the fracture.

- In the intermittent test, approximately $60 \%$ of the fracture saturates before the first discrete sliding droplet is noticed on the vertical wall at 112 seconds (12.4 hours, at prototype scale). Outflow along the vertical wall continues to occur at the localised point of the initial breach by subsequent sliding droplets.

- Unlike the intermittent flow test, full saturation of the horizontal fracture occurs in the continuous flow test in 0.71 seconds ( 4.7 minutes), as shown in the initial wetting phase in Figure 12.

- Upon saturation, a film of approximately $10 \mathrm{~mm}$ width $(200 \mathrm{~mm})$, is observed on the vertical wall with an additional narrow oscillating rivulet (similar to flow mechanism $\mathrm{C}$ in the vertical fracture). Increasing the influx to $40 \mathrm{l} / \mathrm{hr}$ widens the film to approximately $30 \mathrm{~mm}(600 \mathrm{~mm})$, while maintaining oscillation in the rivulet. Upon increasing the influx to $60 \mathrm{l} / \mathrm{hr}$, the film widens to $50 \mathrm{~mm}(1000 \mathrm{~mm})$, and an additional 2 oscillating rivulets form. By $100 \mathrm{l} / \mathrm{hr}$ the width of the film is equivalent to the width of the horizontal fracture. Throughout all intervals, the film at the vertical exit wall sweeps to the right.

- Upon rewetting, the capillary island that formed is mobilised, despite a small capillary island being trapped at the edge of the exit of the horizontal fracture. The water exiting along the vertical face follows the same flow mechanism as previously observed for all influx intervals. 


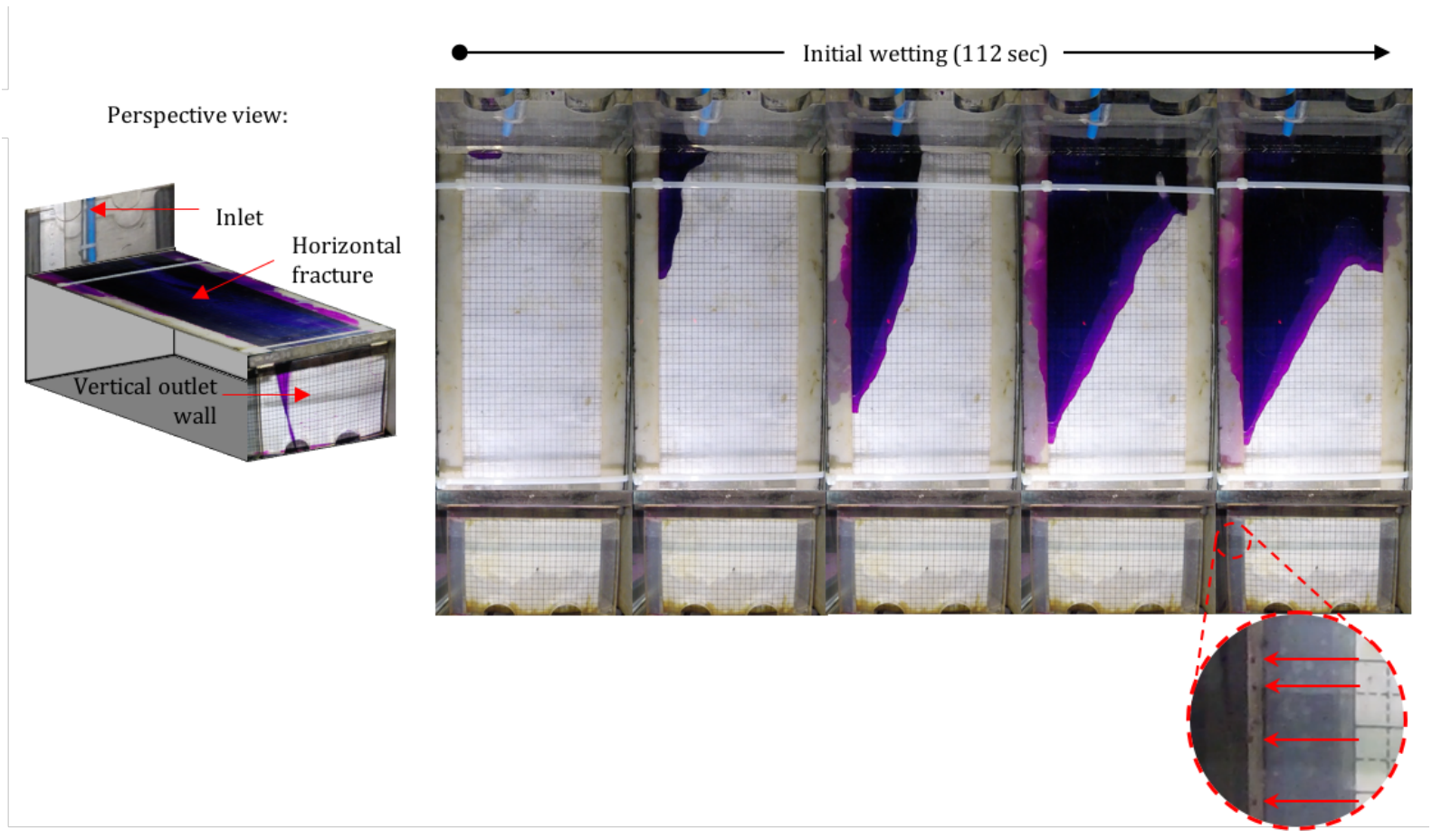

Figure 11. Snapshot of the wetting front of the horizontal fracture for the intermittent (droplet) flow experiment ( $5 \mathrm{~mm} \times 5 \mathrm{~mm}$ grid). The insert shows perspective for the reader (horizontal fracture and unconfined vertical outlet wall), as well as the sliding droplets on the unconfined vertical outlet wall.

The observed flow mechanism A, of the initial invading rivulet, is dissimilar to the mechanism observed at high flow rates observed by Su et al. (1999), in that no prominent air-water meniscus (droplet) proceeds the rivulet. Nevertheless, once established the rivulet is maintained throughout the fracture indicating a similar observation to Su et al. (1999) for rivulets supplied by high flow rate. Furthermore, the discontinuous path of sliding droplets that forms adjacent is also similar to the flow mechanism observed at low flow rates by Su et al. (1999), and furthermore by results published by Ghezzehei and Or (2005). The presence of oscillating rivulets and flow switches (flow mechanism C) indicate flow instabilities in unsaturated fractures, similar to the meandering rivulets presented by Ghezzehei (2004). These flow instabilities are plausibly an indication that the flow through an individual rivulet is approaching a maximum limit, for the specific contact angle and $\mathrm{g}$ level, specific to this test. The observation of non-interacting intersections between meandering rivulets (flow mechanism D), as the two populations of rivulets are flowing on the opposite sides of the fracture walls, is an important observation indicating that the individual rivulets do not fill the fracture gap fully. 

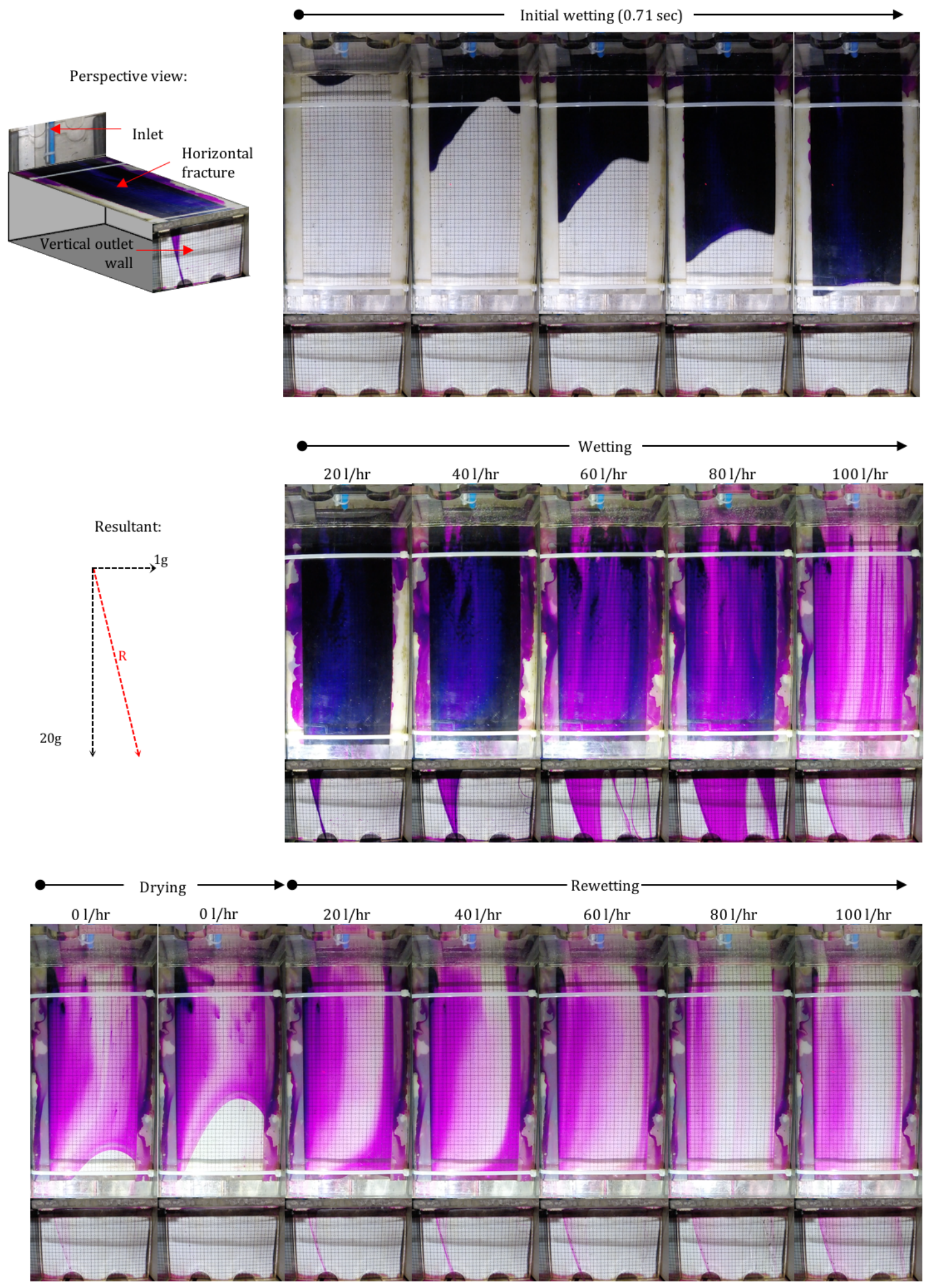

Figure 12. Screenshots of the horizontal fracture and vertical wall for the continuous flow experiment at each interval during the test, under $20 \mathrm{G}$ conditions ( $5 \mathrm{~mm} \times 5 \mathrm{~mm}$ grid). The inserts show perspective for the reader (horizontal fracture and unconfined vertical outlet wall), as well as the resultant force acting on the film on the unconfined vertical outlet wall, causing it to sweep. 
The observation of rivulets, and sliding droplet flow mechanisms, as well as film flow (only in the horizontal experiment) is important. If one considers the phase diagram of Ghezzehei (2004), contact angles of $70^{\circ}$ for the acrylic Plexiglas used (e.g. Aouad et al. 2016; Della Volpe et al. 2002; Sumner et al. 2004) at the flow rates tested, rivulets and sliding droplets should dominate the observed flow mechanisms. The observation of coexisting droplet and rivulet flow mechanisms is likely a function of the test set-up, and not due to the same process as presented by Dragila et al. (2016). In these instances, directly beneath the inlet pipe, there is lateral accumulation of water above the fracture entrance. The continuous rivulet forms directly beneath the inlet pipe and is supplied by the majority of water being introduced. Conversely, the intermittent rivulet is being supplied by the rejected lateral accumulation of water above the fracture entrance, at a much lower flow rate. This discontinuous path of intermittent sliding droplets observed in flow mechanism A, results from water ponding above the fracture growing to some critical size, and forming a thinning neck that eventually snaps, releasing a droplet from the top of the fracture. Similar reason can be used to explain flow mechanism B, whereby a continuous rivulet terminates to a discontinuous path of intermittent sliding droplets. Here a reduced influx for this particular feature, again from a lateral accumulation above the fracture entrance, results in an insufficient quantity of water to establish a fully-continuous rivulet, and instead an intermittent rivulet forms releasing sliding droplets when the weight of the droplet is greater than the surface tension.

The sweeping of the wide films at the vertical wall in the horizontal test is due to a resultant force, due to the interaction between the centripetal force acting perpendicular to the centrifuge platform and gravity force acting towards the centre of the Earth. This influence is only noted for these films with large volumetric fluxes and are plausibly a function of the volume of water being transmitted. The path followed by the sliding droplets and rivulets within the fracture can be attributed to the wetting capability of the material as described by Doe (2001), whereby generally the same cross-sectional drainage area re-saturates during rewetting.

By treating the fracture width as a microscopic length (as discussed by Culligan and Barry 1998), the scaled model results do not accurately represent natural conditions. In this instance, despite the similitude failure of the Capillary and Bond numbers, the Stokes number, which describes gravity driven flow instability, remains constant and suggests that the observed oscillating, meandering, flow switching and merging of rivulets within the model does occur in natural conditions. The observation of similar flow mechanisms in the fracture in the form of sliding droplets, rivulets is consistent with those published in literature. This signifies that although the 
results from the geotechnical centrifuge model may not be scaled to prototype conditions, the observed flow mechanisms and flow instabilities are representative of natural conditions.

This good accordance between flow mechanisms observed in a geotechnical centrifuge and previous research indicates that the geotechnical centrifuge replicates variably saturated flow mechanisms acceptably. An important issue observed in replicating the parallel plate conceptual model is that full saturation is never achieved in any of the vertical fractures (as a required assumption of the cubic law as stated by e.g. SilberhornHemminger et al. 2005; Singhal and Gupta 2010; Zimmerman and Bodvarsson 1996), including that of the vertical wall of the horizontal test where the horizontal fracture is fully saturated. However, considering that the cubic law is an expression for fracture permeability, the flow that you would get through a saturated fracture under the experimental conditions investigated is very likely to be much higher than the imposed flow rate, from the inlet pipe. Furthermore, full saturation is not even achieved in the horizontal fracture during the intermittent test. In a separate study being prepared, the authors (Jones et al. in review) present that a plausible explanation could be in using the continuity principle whereby water should theoretically be transported downward at significantly higher flow rates given the very low degree of water saturation in the vertical fractures compared to horizontal fractures. A reduced rate of input, results in a smaller cross-sectional drainage area and appearance of sliding droplets that form when the weight of the droplets, attached to the ponding of water in the horizontal fracture, are greater than the surface tension of the vertical wall and are released. Therefore, a current prominent challenge is understanding the interaction of film and capillary forces within a fracture, so that multiple flow mechanisms and sporadic flow instabilities can be accurately described and quantified, in assessing flow through more complex natural conditions of the intermediate fractured vadose zone. Despite the difficulties currently being faced, understanding the complex flow regimes and force interactions is a current research area in unsaturated fluid mechanics (e.g. Dragila and Weisbrod 2003; Ghezzehei 2004; Kordilla et al. 2013; Or and Ghezzehei 2007; Su et al. 1999).

\section{CONCLUSIONS}

\subsection{Limitations and lessons learnt}


Research presented in this paper has only investigated homogenous fine sand. Although it was pertinent to assess such fundamental concepts initially, the influence of anisotropy and heterogeneity which exists in the subsurface cannot be ignored. The fracture flow research as discussed in this paper is limited to the smooth parallel perfectly horizontal or vertical acrylic Plexiglas fracture with $1 \mathrm{~mm}$ aperture. In order to further validate the geotechnical centrifuge as a viable tool of modelling rock masses, future research will need to show that it is indeed possible to model the impact that fracture characteristics (as presented by Berkowitz 2002) such as roughness and waviness has on how, rather than how much, flow occurs through discrete fractures under conditions of variable saturation. Geometrical properties will likely become increasingly harder to model when constructing a scaled-down centrifuge model, and therefore could compromise the accurate representation of the contact areas, and the geometry of discrete fracture. In the same light, when considering the scale of fractures, particularly at larger scales; there will be a threshold aperture were a fracture become macroscopic and not microscopic, and potentially contest the reasoning of Culligan and Barry (1998).

\subsection{Main findings}

Findings from the research presented in this paper show that the hydraulic gradient and not the hydraulic conductivity is scaled for seepage flow in the geotechnical centrifuge. Furthermore, geotechnical centrifuge modelling has been proven as a viable experimental tool for the modelling of hydrodynamic dispersion as well as the replication of similar flow mechanisms for unsaturated fracture flow, as previously observed in literature. In these fundamental experimental models, despite full saturation being achieved for high flow rates in a horizontal fracture, flow through the vertical fracture violates assumptions of the cubic law where full saturation is never achieved and flow is neither uniform, nor laminar. If such an ideal model is unable to duplicate the assumptions of the cubic law, its use in numerical models should be queried in the intermediate fractured vadose zone.

Despite the imminent challenges of modelling variable saturation in the vadose zone, the geotechnical centrifuge offers a powerful experimental tool to physically model and observe variably saturated flow. Although an exact reproduction of unsaturated fracture flow is not likely achieved using the geotechnical centrifuge, it does have a valuable role to play in delineating and understanding the physical mechanisms that control this complex problem. This can be used to give valuable insight into mechanisms associated with solid-fluid interaction 
problems under conditions of variable saturation. Findings from future research can be used to validate current numerical modelling techniques and address the subsequent influence on aquifer recharge and vulnerability, contaminant transport, waste disposal, dam construction, slope stability and seepage into subsurface excavations. Oversimplification of the influence of the vadose zone through for instance: black box modelling; simplification to basic primary porosity systems; consideration of only saturated hydraulic parameters; and the like, result in a misrepresentation of the role of the vadose zone in hydrological systems. Most models may potentially fail due to this lack of input. Further to this, the typical vadose zone comprising soil overlying fractured rock can be better modelled with improved understanding of how these two media behave individually, but more importantly in a combined sequence.

\section{ACKNOWLEDGEMENTS}

The authors wish to acknowledge the Water Research Commission of South Africa (www.wrc.org.za) for funding of project K5/2052 on Multidisciplinary Vadose Zone Hydrology, as well as project K5/2326 on Quantification of Unsaturated Flow in the Fractured Intermediate Vadose Zone by means of Geotechnical Centrifuge (to be published by the WRC in 2016). Furthermore, acknowledgement is extended to Prof S.W. Jacobsz and Prof J.L. Van Rooy for their guidance and input into this paper. Gratitude is also extended to the National Research Foundation (NRF) as well as Exxaro Resources Ltd, for their financial assistance to some of the authors of this paper. The authors declare no conflict of interest.

\section{REFERENCES}

Aouad W, Landel JR, Dalziel SB, Davidson JF, Wilson DI (2016) Particle image velocimetry and modelling of horizontal coherent liquid jets impinging on and draining down a vertical wall Experimental Thermal and Fluid Science 74:429-443 doi:http://dx.doi.org/10.1016/j.expthermflusci.2015.12.010

Archer A (2014) Using small-strain stiffness to predict the settlement of shallow foundations. Unpublished MEng dissertation, Pretoria: University of Pretoria.[Links]

Aydin A (2001) Fracture void structure: implications for flow, transport and deformation Environmental Geology : International Journal of Geosciences 40:672-677 
Aziz C, Newell C, Gonzales J, Haas P, Clement T, Sun Y (2000) BIOCHLOR Natural Attenuation Decision Support System. User's Manual Version 1.0 US Environmental Protection Agency

Barry D, Lisle I, Li L, Prommer H, Parlange JY, Sander GC, Griffioen J (2001) Similitude applied to centrifugal scaling of unsaturated flow Water Resources Research 37:2471-2479

Basha H, Mina N (1999) Estimation of the unsaturated hydraulic conductivity from the pressure distribution in a centrifugal field Water resources research 35:469-477

Bear J (1972) Dynamics of fluids in porous media American Else-vier, New York

Berkowitz B (2002) Characterizing flow and transport in fractured geological media: A review Advances in Water Resources 25:861-884 doi:http://dx.doi.org/10.1016/S0309-1708(02)00042-8

Butterfield R (2000) Scale-Modelling of Fluid Flow in Geotechnical Centrifuges Journal of the Japanese Geotechnical Society: Soils and Foundation 40:39-45

Cecconi M, Croce P, Viggiani G Physical modelling of block toppling. In: Physical Modelling in Geotechnics, Two Volume Set: Proceedings of the Sixth International Conference on Physical Modelling in Geotechnics, 6th ICPMG'06, Hong Kong, 4-6 August 2006, 2006. CRC Press, p 325

Chen ZY, Zhang JH, Wang WX, Xing YC (2006) Centrifuge modelling of rock slopes. In: Ng CW, Wang Y-H, Zhang L (eds) Physical Modelling in Geotechnics, Two Volume Set: Proceedings of the Sixth International Conference on Physical Modelling in Geotechnics, 6th ICPMG'06, Hong Kong, 4-6 August 2006, vol 1. CRC Press, pp 19-28

Chikatamarla R, Laue J, Springman S Modelling of rockfall on protection galleries. In: 6th International Conference on Physical Modelling in Geotechnics, 2006. pp 331-336

Cook N (1992) Natural joints in rock: Mechanical, hydraulic and seismic behaviour and properties under normal stress International Journal of Rock Mechanics and Mining Sciences \& Geomechanics Abstracts 29:198-223

Culligan P, Barry D (1998) Similitude requirements for modelling NAPL movement with a geotechnical centrifuge Proc Instn Civ Engrs Geotech Engng:180-186

Culligan-Hensley PJ, Savvidou C (1995) Environmental geomechanics and transport processes In: Taylor R (ed) Geotechnical centrifuge technology. CRC Press, pp 201-271

Della Volpe C, Maniglio D, Morra M, Siboni S (2002) The determination of a 'stable-equilibrium'contact angle on heterogeneous and rough surfaces Colloids and Surfaces A: Physicochemical and Engineering Aspects 206:47-67 
Delleur JW (2006) Elementary Groundwater Flow and Transport Processes In: Delleur JW (ed) The handbook of groundwater engineering. CRC press, pp 3.1-3.45

Dippenaar MA (2012) How we lose ground when earth scientists become territorial: defining "soil” Natural resources research 21:137-142

Dippenaar MA (2014) Porosity reviewed: quantitative multi-disciplinary understanding, recent advances and applications in vadose zone hydrology Geotechnical and Geological Engineering 32:1-19

Dippenaar MA, Van Rooy JL (2016) On the cubic law and variably saturated flow through discrete open roughwalled discontinuities International Journal of Rock Mechanics and Mining Sciences 89:200-211 doi:http://dx.doi.org/10.1016/j.ijrmms.2016.09.011

Dippenaar MA, van Rooy JL, Breedt N, Huisamen A, Muravha SE, Mahlangu S, Mulders JA (2014) Vadose zone hydrology: Concepts and techniques. Water Research Commision (WRC), Pretoria

Doe TW (2001) What do drops do? Surface wetting and network geometry effects on vadose-zone fracture flow Conceptual models of flow and transport in the fractured vadose zone:243-270

Dragila MI, Hay KM, Wheatcraft SW (2016) 9. Initial pipe development within epikarst microfractures Geological Society of America Special Papers 516:129-136

Dragila MI, Weisbrod N (2003) Parameters affecting maximum fluid transport in large aperture fractures Advances in Water Resources 26:1219-1228

Einstein HH, Li V, Whitman RV, Veneziano D, Reyes O, Iglesia G, Lee J-S (1990) Stochastic and Centrifuge Modelling of Jointed Rock. DTIC Document,

Fetter C (2001) Applied hydrogeology, Fourth edn. Prentice-Hall, New Jersey

Garnier J et al. (2007) Catalogue of scaling laws and similitude questions in geotechnical centrifuge modelling International Journal of Physical Modelling in Geotechnics 7:1

Ghezzehei TA (2004) Constraints for flow regimes on smooth fracture surfaces Water Resources Research 40:n/a-n/a doi:10.1029/2004WR003164

Ghezzehei TA, Or D (2005) Liquid fragmentation and intermittent flow regimes in unsaturated fractured media Water resources research 41

Gudmundsson A, Gjesdal O, Brenner SL, Fjeldskaar I (2003) Effects of linking up of discontinuities on fracture growth and groundwater transport Hydrogeology Journal 11:84-99 doi:10.1007/s10040-002-0238-0

Günzel F, Davies M Influence of warming permafrost on the stability of ice filled rock joints. In: Proceedings, 6th International Conference on Physical Modelling in Geotechnics, 2006. pp 343-348 
Hakami E, Larsson E Aperture measurements and flow experiments on a single natural fracture. In: International Journal of Rock Mechanics and Mining Sciences \& Geomechanics Abstracts, 1996. vol 4. Elsevier, pp $395-404$

Hensley P, Randolph M Modelling contaminant dispersion in saturated sand. In: Proceedings of the international conference on soil mechanics and foundation engineering-international society for soil mechanics and foundation engineering, 1994. AA Balkema, pp 1557-1557

Hoek E, Bray J (1981) Rock slope engineering. Rev. 3rd ed. edn. Institution of Mining and Metallurgy, London :

Indraratna B, Ranjith P (2001) Hydromechanical aspects and unsaturated flow in jointed rock. A.A. Balkema Publishers, Lisse [Netherlands] ;

Itoh K, Toyosawa Y, Kusakabe O, Ng C, Zhang L, Wang Y Centrifugal modelling of rockfalls. In: Proceedings of the 6th International Conference on Physical Modelling in Geotechnics-ICPMG, Hong Kong (Ng CWW, Zhang LM and Wang YH (eds)). Taylor \& Francis, London, UK, 2006. pp 349-354

Jacobsz S, Kearsley E, Kock J The geotechnical centrifuge facility at the University of Pretoria. In: ICPMG2014-Physical Modelling in Geotechnics: Proceedings of the 8th International Conference on Physical Modelling in Geotechnics 2014 (ICPMG2014), Perth, Australia, 14-17 January 2014, 2014. CRC Press, p 169

Jones BR, Brouwers LB, Dippenaar MA (in review) Initially dry vertical fractures fail to saturate under freedraining conditions International Journal of Rock Mechanics and Mining Sciences Manuscript Number: IJRMMS-S-16-00410

Joseph P, Einstein H (1988) Rock modeling using the centrifuge. DTIC Document,

Knappett J, Craig RF (2012) Craig's soil mechanics. Spon Press,

Kordilla J, Tartakovsky AM, Geyer T (2013) A smoothed particle hydrodynamics model for droplet and film flow on smooth and rough fracture surfaces Advances in Water Resources 59:1-14 doi:http://dx.doi.org/10.1016/j.advwatres.2013.04.009

Kumar P (2007) Scaling laws and experimental modelling of contaminant transport mechanism through soils in a geotechnical centrifuge Geotechnical and Geological Engineering 25:581-590

Lee C-H, Farmer IW (1993) Fluid flow in discontinuous rocks. 1st ed. edn. Chapman \& Hall, London ;

Levy LC, Culligan PJ, Germaine JT (2002) Use of the geotechnical centrifuge as a tool to model dense nonaqueous phase liquid migration in fractures Water resources research 38 
Levy LC, Culligan PJ, Germaine JT (2003) Modelling of DNAPL behavior in vertical fractures International Journal of Physical Modelling in Geotechnics 3:01-18

Li X, Wartman J, Tang H, Yan J, Luo H, Hu W (2014) Dynamic Centrifuge Modelling Tests for Sliding Rock Slopes. In: Landslide Science for a Safer Geoenvironment. Springer, pp 75-79

Liu H-H, Wei M-Y, Rutqvist J (2013) Normal-stress dependence of fracture hydraulic properties including twophase flow properties Hydrogeology Journal : Official Journal of the International Association of Hydrogeologists 21:371-382

Mattson ED, Palmer C, Smith RW, Flury M (2010) Centrifuge techniques and apparatus for transport experiments in porous media vol 1. Taylor and Francis Group: London,

Neuman SP (2005) Trends, prospects and challenges in quantifying flow and transport through fractured rocks Hydrogeology Journal 13:124-147

Nimmo JR (1990) Experimental Testing of Transient Unsaturated Flow Theory at Low Water Content in Water Resources Research 26:1951-1960

Nimmo JR (2006) Unsaturated zone flow processes Encyclopedia of Hydrological Sciences

Nimmo JR, Akstin KC, Mello KA (1992) Improved apparatus for measuring hydraulic conductivity at low water content Soil Science Society of America Journal 56:1758-1761

Nimmo JR, Mello KA (1991) Centrifugal techniques for measuring saturated hydraulic conductivity Water Resources Research 27:1263-1269

Nimmo JR, Rubin J, Hammermeister D (1987) Unsaturated flow in a centrifugal field: Measurement of hydraulic conductivity and testing of Darcy's law Water Resour Res 23:124-134

Or D, Ghezzehei TA (2007) Traveling liquid bridges in unsaturated fractured porous media Transport in Porous Media 68:129-151

Or D, Tuller M (2000) Flow in unsaturated fractured porous media: Hydraulic conductivity of rough surfaces Water Resources Research 36:1165-1177

Phillips R (1995) Centrifuge modelling: practical considerations Geotechnical centrifuge technology:34-60 Poehls D, Smith GJ (2011) Encyclopedic dictionary of hydrogeology. Academic Press,

Pyrak LR, Myer LR, Cook NGW (1985) Determination of fracture void geometry and contact area at different effective stress. Eos Trans AGU 66

Raven KG, Gale JE (1985) Water flow in a natural rock fracture as a function of stress and sample size International Journal of Rock Mechanics and Mining Sciences 22:251-261 
Robinson R (2002) Modelling hydraulic conductivity in a small centrifuge: Discussion Canadian Geotechnical Journal 39:486-487

Rumynin VG (2011) Water Movement and Solute Transport in Unsaturated Porous Media. In: Subsurface Solute Transport Models and Case Histories. Springer, pp 77-119

Silberhorn-Hemminger A, Süß M, Helmig R (2005) Natural fractured porous systems. In: Dietrich P, Helmig, R., Sauter, M., Hötzl, H., Köngeter, J., and Teutsch, G. (ed) Flow and transport in fractured porous media. . Springer, Berlin, pp 16-24

Šimůnek J, Nimmo JR (2005) Estimating soil hydraulic parameters from transient flow experiments in a centrifuge using parameter optimization technique Water resources research 41

Singh DN, Gupta AK (2000) Modelling hydraulic conductivity in a small centrifuge Canadian Geotechnical Journal 37:1150-1155

Singh DN, Gupta AK (2002) Modelling hydraulic conductivity in a small centrifuge: Reply Canadian Geotechnical Journal 39:488-489

Singhal BBS, Gupta RP (2010) Applied hydrogeology of fractured rocks. 2nd ed. edn. Springer, Dordrecht ;

Sisavath S, Al-Yaaruby A, Pain CC, Zimmerman RW (2003) A Simple Model for Deviations from the Cubic Law for a Fracture Undergoing Dilation or Closure Pure and Applied Geophysics 160:1009-1022

Stone KJL, Maquin M, Richards DJ, Montouchet M (2013) Physical and numerical modeling of problems in homogeneous and fractured soft rock masses. In: ICPMG2014 Physical Modelling in Geotechnics. CRC Press, pp 413-417. doi:10.1201/b16200-53

Su GW, Geller JT, Pruess K, Wen F (1999) Experimental studies of water seepage and intermittent flow in unsaturated, rough-walled fractures Water Resources Research 35:1019-1037

Sumner AL et al. (2004) The nature of water on surfaces of laboratory systems and implications for heterogeneous chemistry in the troposphere Physical Chemistry Chemical Physics 6:604-613 doi:10.1039/B308125G

Taylor R (1995) Centrifuges in modelling: Principles and scale effects. In: Taylor R (ed) Geotechnical centrifuge technology. CRC Press, pp 20-34

Tokunaga TK, Wan J (1997) Water film flow along fracture surfaces of porous rock Water Resources Research 33:1287-1295

Tokunaga TK, Wan J (2001) Approximate boundaries between different flow regimes in fractured rocks Water Resources Research 37:2103-2111 
Van Tonder W (2016) Centrifuge Modelling of Permeability of a Heterogeneous Coal Mine Backfill Sequence. Unpublished MSc Dissertation, University of Pretoria

Weiss M, Rubin Y, Adar E, Nativ R (2006) Fracture and bedding plane control on groundwater flow in a chalk aquitard Hydrogeology Journal 14:1081-1093

Wiedemeier TH, Wilson JT, Hansen JE, Chapelle FH, Swanson MA (1996) Technical Protocol for Evaluating Natural Attenuation of Chlorinated Solvents in Groundwater. Revision 1. DTIC Document,

Witherspoon PA (1986) Flow of groundwater in fractured rocks Bulletin of the International Association of Engineering Geology 34:103-115

Witherspoon PA, Wang JSY, Iwai K, Gale JE (1980) Validity of Cubic Law for fluid flow in a deformable rock fracture Water Resources Research 16:1016-1024

Zimmerman RW, Bodvarsson GS (1996) Hydraulic conductivity of rock fractures Transport in Porous Media 23:1-30

Zornberg JG, McCartney JS (2010) Centrifuge permeameter for unsaturated soils. I: Theoretical basis and experimental developments Journal of Geotechnical and Geoenvironmental Engineering 136:1051-1063 